\title{
Energy Options in an HJM Framework
}

\author{
Lyse Hansen, Thomas; Astrup Jensen, Bjarne
}

Document Version

Final published version

Publication date:

2004

\section{License \\ CC BY-NC-ND}

Citation for published version (APA):

Lyse Hansen, T., \& Astrup Jensen, B. (2004). Energy Options in an HJM Framework.

Link to publication in CBS Research Portal

\section{General rights}

Copyright and moral rights for the publications made accessible in the public portal are retained by the authors and/or other copyright owners and it is a condition of accessing publications that users recognise and abide by the legal requirements associated with these rights.

\section{Take down policy}

If you believe that this document breaches copyright please contact us (research.lib@cbs.dk) providing details, and we will remove access to the work immediately and investigate your claim. 
WP 2004-10

Energy Options in an HJM Framework

by

Thomas Lyse Hansen and Bjarne Astrup Jensen

INSTITUT FOR FINANSIERING, Handelshøjskolen i København Solbjerg Plads 3, 2000 Frederiksberg C tlf.: 38153615 fax: 38153600

DEPARTMENT OF FINANCE, Copenhagen Business School

Solbjerg Plads 3, DK - 2000 Frederiksberg C, Denmark Phone (+45)38153615, Fax (+45)38153600

www.cbs.dk/departments/finance

ISBN 87-90705-85-8

ISSN 0903-0352 


\title{
Energy Options in an HJM Framework
}

\author{
Thomas Lyse Hansen ${ }^{1}$ and Bjarne Astrup Jensen ${ }^{2}$
}

This version:

5th January 2005

${ }^{1}$ DONG A/S, Agern Alle 24-26, DK-2970 Hørsholm. (tlha@dong.dk).

${ }^{2}$ Department of Finance, Copenhagen Business School, Solbjerg Plads 3, DK-2000 Frederiksberg. (ba.fi@cbs.dk). We thank for comments on earlier versions from Tomas Björk, Jørgen Aase Nielsen and participants in the Arne Ryde workshop at Lund University. The authors gratefully acknowledge financial support from the Danish Social Research Council. 


\section{Introduction}

It is a delicate matter to trade spot products and financial derivatives in energy markets. Opposite to bond and stock markets, the underlying assets are real products and a significant part of the demand for them represents a real need for the products, which can only be substituted away with some difficulties or, in some cases, only in a prohibitively costly manner. This is particularly true in the spot market, where the demand is almost always met, but where the spot price processes can be quite different from the spot price processes conventionally used in the pricing of derivatives. This pattern of real demand is also the main reason for the existence of the well-known convenience yield in energy markets.

Actually, convenience yields exist in most commodity markets which are not primarily driven by speculation, cf. Brennan (1991). A popular and widely used definition of net convenience yield of a commodity is given in Brennan (1991) as

"the flow of services that accrues to the holder of a physical commodity, but not to the owner of a contract for future delivery - measured per unit time and unit of the commodity."

In order to explain what convenience yield implies for the pricing and hedging of energy derivatives, convenience yield is often compared to (continuously paid) dividends on common stocks. This is a good first explanation. However, the dynamics of convenience yields in energy markets is typically very different from the modest dynamics of stock dividends, where an assumption about a constant continuously paid dividend rate or discretely paid fixed amounts is often sufficient to make a derivatives pricing model work well. Opposite to this, modelling of convenience yields on energy commodities requires a more sophisticated approach, because empirical evidence clearly states that convenience yields are stochastic. Furthermore, it shows the existence of a significant term structure of convenience yields. This calls for a modelling approach in the spirit of Heath, Jarrow, and Morton (1992), abbreviated HJM, where the spot price and the initial term structure of futures prices are taken as given. Based on this the drift of the convenience yield under an equivalent martingale measure is derived.

Obviously, the spot prices of energy has to be modelled as a stochastic process too. Furthermore, the introduction of a stochastic exchange rate is important for energy investors in almost any other country than the US, the prime example being crude oil and oil products that are almost exclusively traded in US dollars. Unless otherwise stated it is understood that energy commodities are internationally traded commodities with identical exchange rate adjusted spot prices in different markets. This is no restriction whenever the different currencies are used solely as units of account. But whenever the use of different currencies are used to compare spot 
prices in geographically separated areas it is no longer obvious that the exchange rate adjusted spot prices are identical. Transportation costs and delivery time (e.g. oil and related products), physical constraints in transmission capacity or the entire lack of such capacity (e.g. natural gas, electricity) and even politically determined flow constraints (e.g. oil export tariffs from Russia) are frictions that may cause markets to separate such that the exchange rate adjusted prices can no longer be assumed identical. However, such frictions due to the real nature of the commodities are not modelled within this paper.

The electricity market is the prime example where some of the basic assumptions and properties underlying conventional derivatives pricing models do not apply. This is due to the lack of storeability outside the hydropower based markets. Hence, neither the conventional hedging techniques for the pricing of financial derivatives nor the ability to learn about an appropriate equivalent martingale measure from the spot market apply. Similarly, it is meaningless to interpret the convenience yield as a flow of services to an investor from holding an inventory. In this case one can, of course, always give up the usual interpretation of the convenience yield and define it in a backwards manner such that the usual no arbitrage based pricing relations are valid. On the other hand, electricity is also an example of a real good that can be transported instantly over long distances, provided the relevant transmission lines have been established.

When volatilities are assumed to be deterministic the model simplifies considerably and becomes more operational; we show how simple option pricing formulas fully analogous to the Black-Scholes formula are obtained. Further simplifications are obtained when interest rates are assumed to be deterministic. This is quite reasonable since they are only weakly correlated with energy prices, convenience yields and exchange rates. Moreover, the magnitude of their variation is much smaller than the variation of the other factors; hence, only little is lost by doing so.

The reader familiar with Miltersen and Schwartz (1998) will realize that this set-up is heavily inspired by theirs. However, while they allow the interest rate to be stochastic they do not consider exchange rate risk. Furthermore, our work differs from theirs by extending the analysis to derivatives, where the underlying energy commodity is allowed to be either a portfolio of single-delivery contracts or a flow forward. A flow forward means that the commodity is delivered continuously through some specified period as opposed to the standard single-delivery energy commodity like crude oil or cracked oil products, where the delivery of the entire bulk takes place at a single point in time. The relevant energy commodities with flow feature are electricity and natural gas. Our approach to cope with the flow feature is to view the contract as an indivisible portfolio of periodical (weekly or daily) single-delivery forwards. This makes it possible to price an option on the flow contract which is an option on a sum of $n$ single-delivery forwards as a multiple of an option, which is written on a single-delivery forward, following the approach 
of Jamshidian (1989) ${ }^{1}$ and, especially, the extension for multi-factor models by Munk (1999). This approach to option pricing is only an approximate pricing method. However, Monte Carlo simulation results show that this approximation method is indeed quite accurate.

The paper is organized as follows. Section 2 outlines the set-up and section 3 describes our basic model for energy options, where the underlying is allowed either to be a portfolio of singledelivery futures or forwards with a flow feature (flow forwards). Potential applications to two different energy markets is discussed in section 4 . Section 5 describes our results from comparing the approximate pricing method with the results from a Monte Carlo simulation which produces the correct theoretical prices that are not obtainable in analytical form. Concluding remarks end the paper in section 6 .

\section{The set-up}

A similar description of the model setup as given in this section 2 can be found in Miltersen and Schwartz (1998). However, considering only the one country/currency case they do not incorporate a stochastic exchange rate in their model.

\subsection{The basics without exchange rate risk}

It is assumed that pricing and trading of the energy commodities and derivatives is done in one single country. So, by construction there is no exchange rate risk.

Current time is $t_{0}$ and the finite investment horizon is $\bar{T}>t_{0}$. The relevant probability space upon which the objective probability measure $\mathbf{P}$ works is denoted $\left(\Omega,\left(\mathcal{F}_{t}\right)_{0 \leq t \leq \bar{T}}, \mathbf{P}\right)$, where $\mathcal{F}_{t}=\sigma\left(W_{u} \mid 0 \leq u \leq t\right)$. Assume that the following stochastic processes are defined on the probability space:

- the spot price of the underlying energy commodity $\left(S_{t}\right)$

- the spot interest rate $\left(r_{t}\right)$

- the family of zero-coupon bond prices, $\left\{P\left(t_{0}, T\right)\right\}_{t_{0} \leq t \leq T \leq \bar{T}}$

- the family of futures prices $\{F(t, T)\}_{t_{0} \leq t \leq T \leq \bar{T}}$

- the family of forward prices $\{G(t, T)\}_{t_{0} \leq t \leq T \leq \bar{T}}$

\footnotetext{
${ }^{1}$ In Jamshidian (1989) it is shown how to price an option on a coupon bond as a sum of options, each of them written on one of the zero-coupon bonds, which constitute the coupon bond.
} 
All stochastic processes are written with surrounding $(\cdot)$ to emphasize that they are indeed processes. A set of stochastic processes or variables that are naturally connected is written with surrounding parentheses $\{\cdot\}$. For technical reasons all processes are required to be $\mathcal{H}_{2}(\mathbf{P})$ processes, meaning that all the stochastic integrals w.r.t. the Wiener process are not only welldefined, but are $\mathbf{P}$-continuous square integrable martingales ${ }^{2}$.

In accordance with standard assumptions in the literature we assume the existence of the usual equivalent martingale measure $\mathbf{Q}$ with the bank account $\beta_{t} \equiv \beta_{0} \exp \left(\int_{0}^{t} r_{s} d s\right)$ as the numeraire. Later on we will work with several other $\mathbf{P}$-equivalent measures with associated numeraire processes, so we need to be specific about which measure is involved.

Continuously compounded forward interest rates $(f(t, s))$ are defined by

$$
P(t, T)=\mathrm{E}^{\mathbf{Q}}\left[e^{-\int_{t}^{T} r_{s} d s} \mid \mathcal{F}_{t}\right]=e^{-\int_{t}^{T} f(t, s) d s}
$$

Continuously compounded forward convenience yields $(\delta(t, s))$ are defined in a similar manner by the forward prices as

$$
G(t, T)=\frac{S_{t}}{P(t, T)} e^{-\int_{t}^{T} \delta(t, s) d s}=S_{t} e^{\int_{t}^{T}(f(t, s)-\delta(t, s)) d s}
$$

while continuously compounded futures convenience yields $(\epsilon(t, s))$ are defined by the futures prices as

$$
F(t, T)=\frac{S_{t}}{P(t, T)} e^{-\int_{t}^{T} \epsilon(t, s) d s}=S_{t} e^{\int_{t}^{T}(f(t, s)-\epsilon(t, s)) d s}
$$

The economic interpretation of the continuously compounded forward convenience yield $\delta(t, s)$ is that it is a "non-pecuniary dividend yield", cf. Brennan (1991), as mentioned in the introduction. There is no similar easy interpretation of the futures convenience yield, because of the continuous resettlement payment structure for futures contracts. However, when interest rates are deterministic the forward prices and the futures prices are identical; hence, the two convenience yield curves are necessarily also identical. The difference arises solely from the interaction of the continuous resettlement feature with the stochastic variation in the interest rate process. It is a pure definition, although a very useful one. Due to the martingale property of futures prices w.r.t. to the $\mathbf{Q}$ measure it is easier to develop models for the stochastic dynamics of futures prices than for similar forward prices.

Differentiating the $P(t, T)$ equation w.r.t. $T$ and taking the limit as $T \downarrow t$, one gets the well-known relationship between spot and forward interest rates

$$
f(t, t)=r_{t} \quad \forall t
$$

Finally it is worth noting that the futures and forward contracts for instantaneous delivery must equal the spot price

$$
G(t, t)=F(t, t)=S_{t} \quad \forall t
$$

\footnotetext{
${ }^{2} \mathcal{H}_{2}(\mathbf{P})=\left\{\left(Y_{t}\right)\right.$ a progressively measurable real process $\mid \mathrm{E}^{\mathbf{P}}\left[\int_{0}^{t} Y_{s}^{2} d s\right]<\infty$ for all $\left.t>0\right\}$
} 


\subsection{The basics with exchange rate risk}

Now we assume that the trading of energy commodities (spot and forward/futures) is done in one country with another currency than the one used in the country where the energy derivatives are being priced and traded. The former country is denoted the foreign country and the latter the domestic country. Thus, the situation is seen from the point of view of the domestic country. All foreign variables are written with superscript * as commonly used in two country models in economic literature to identify the "foreign" country.

We have to add two elements to the set-up from the situation without exchange rate risk. These two elements are the forward interest curve for the foreign country, $\left\{f^{*}\left(t_{0}, s\right)\right\}_{t_{0} \leq s \leq \bar{T}}$ and a process $\left(x_{t}\right)$ for the spot exchange rate. $x_{t}$ is quoted as units of domestic currency per unit of foreign currency. The connection between forward rates and zero-coupon bond prices is, of course, the same as in the case without exchange rate risk. However, one should apply the foreign equivalent martingale measure - denoted as $Q^{*}$ - when stating the relationship between foreign forward rates and zero-coupon bond prices. Hence, we will elaborate a bit on the relationship between the two measures $Q$ and $Q^{*}$.

The domestic spot price $S_{t}$ and the foreign spot price $S_{t}^{*}$ is directly related through the exchange rate, i.e. $S_{t}=x_{t} S_{t}^{*}$. Hence, the connection between the continuously compounded convenience yields, $(\delta(t, s))$ and $(\epsilon(t, s))$, and the domestic forward and futures prices is given as

$$
\begin{aligned}
& G(t, T)=S_{t} e^{\int_{t}^{T}(f(t, s)-\delta(t, s)) d s}=x_{t} S_{t}^{*} e^{\int_{t}^{T}(f(t, s)-\delta(t, s)) d s} \\
& F(t, T)=S_{t} e^{\int_{t}^{T}(f(t, s)-\epsilon(t, s)) d s}=x_{t} S_{t}^{*} e^{\int_{t}^{T}(f(t, s)-\epsilon(t, s)) d s}
\end{aligned}
$$

The analogous definitions for the continuously compounded convenience yields, $\left(\delta^{*}(t, s)\right)$ and $\left(\epsilon^{*}(t, s)\right)$, and the foreign forward and futures prices are defined as

$$
\begin{aligned}
& G^{*}(t, T)=S_{t}^{*} e^{\int_{t}^{T}\left(f^{*}(t, s)-\delta^{*}(t, s)\right) d s} \\
& F^{*}(t, T)=S_{t}^{*} e_{t}^{\int_{t}^{T}\left(f^{*}(t, s)-\epsilon^{*}(t, s)\right) d s}
\end{aligned}
$$

Intuitively, forward convenience yields, being rates analogous to dividend yields, should be identical in the foreign and the domestic country. This is proven as the following Theorem 1. However, the futures dividend yields processes, reflecting a possible correlation pattern between the price of the underlying asset and the interest rate process, will in general be different processes.

We apply the notation $E_{t}[X]$ to denote the conditional expected value of $X$ given the $\sigma$-algebra $\mathcal{F}_{t}$. Similarly, we denote the Radon-Nikodym derivative, relative to the $\sigma$-algebra $\mathcal{F}_{t}$, between two equivalent probability measures $P$ and $Q$ as $\left.\frac{d Q}{d P}\right|_{\mathcal{F}_{t}}$. 
Theorem 1 Forward convenience yields as defined in equations (2.6) and (2.8) are identical. When the futures price processes and the forward price processes are identical the futures convenience yields, as defined in equations (2.7) and (2.9), are identical and identical to the forward convenience yields.

When the futures price processes and the forward price processes differ the futures convenience yields will only be identical by coincidence.

Proof First, consider a situation where an arbitrageur enters into two opposite forward positions, one in domestic currency and another in foreign currency. Each of these contracts have zero present value, hence the portfolio of opposite positions also has zero present value. The final settlement payment, expressed in domestic currency, is

$$
x_{T} G^{*}(t, T)-G(t, T)
$$

The zero present value of this position leads to the relations

$$
\begin{array}{rlrl}
E_{t}^{Q}\left[e^{-\int_{t}^{T} r_{s} d s}\left(x_{T} G^{*}(t, T)-G(t, T)\right)\right] & =0 & & \Leftrightarrow \\
E_{t}^{Q}\left[x_{T} e^{-\int_{t}^{T} r_{s} d s}\right] G^{*}(t, T) & =G(t, T) P(t, T) & & \Leftrightarrow \\
x_{t} P^{*}(t, T) G^{*}(t, T) & =G(t, T) P(t, T) & & \Leftrightarrow \\
x_{t} S_{t}^{*} e^{-\int_{t}^{T} \delta^{*}(t, s) d s} & =S_{t} e^{-\int_{t}^{T} \delta(t, s) d s} & & \Leftrightarrow \\
\int_{t}^{T} \delta^{*}(t, s) d s & =\int_{t}^{T} \delta(t, s) d s &
\end{array}
$$

Since this holds for all $T$ we conclude that $\delta(t, T)=\delta^{*}(t, T)$ for all $T$. Alternatively stated, the domestic forward price is the foreign forward price converted at the forward exchange rate:

$$
G(t, T)=\left(x_{t} \frac{P^{*}(t, T)}{P(t, T)}\right) G^{*}(t, T)
$$

For futures contracts recall the well known fact that the futures price $F(t, T)$ is a $Q$-martingale and, analogously, that the futures price $F^{*}(t, T)$ is a $Q^{*}$-martingale. The Radon-Nikodym derivative, cf. Andreasen (1995), is

$$
\left.\frac{d Q}{d Q^{*}}\right|_{\mathcal{F}_{t}}=\frac{x_{t}}{x_{T}} e^{\int_{t}^{T}\left(r_{s}-r_{s}^{*}\right) d s}
$$

Identical futures convenience yields is equivalent to having (2.13) fulfilled for the futures prices, i.e.

$$
x_{t} P^{*}(t, T) F^{*}(t, T)=P(t, T) F(t, T)
$$

This is equivalent to

$$
E_{t}^{Q^{*}}\left[x_{t} P^{*}(t, T) \frac{S_{T}}{x_{T}}\right]=E_{t}^{Q}\left[P^{*}(t, T) e^{\int_{t}^{T}\left(r_{s}^{*}-r_{s}\right) d s} S_{T}\right]=E_{t}^{Q}\left[P(t, T) S_{T}\right]
$$


This will only be fulfilled by coincidence. If forward and futures prices only differ in one currency, e.g. because the interest rate is only stochastic in one country, it is clearly impossible to have (2.18) fulfilled. As another example, consider the widely used specification of the exchange rate process as a process with a constant or deterministic drift. As will be shown later on, cf. (2.28), this drift term equals the interest rate differential $\left(r_{s}-r_{s}^{*}\right)$ under the measure $Q$. In that case the fulfilment of (2.19) boils down to whether the exchange rate process $\frac{x_{T}}{x_{t}}$ is (Q-) uncorrelated with the domestic discount factor:

$$
\begin{aligned}
P^{*}(t, T) & =E_{t}^{Q^{*}}\left[e^{-\int_{t}^{T} r_{s}^{*} d s}\right]=E_{t}^{Q^{*}}\left[e^{-\int_{t}^{T}\left(r_{s}^{*}-r_{s}\right) d s} e^{-\int_{t}^{T} r_{s} d s}\right] \\
& =e^{-\int_{t}^{T}\left(r_{s}^{*}-r_{s}\right) d s} E_{t}^{Q}\left[\frac{x_{T}}{x_{t}} e^{\int_{t}^{T}\left(r_{s}^{*}-r_{s}\right) d s} e^{-\int_{t}^{T} r_{s} d s}\right] \\
& =e^{-\int_{t}^{T}\left(r_{s}^{*}-r_{s}\right) d s} P(t, T)+\operatorname{Cov}_{t}^{Q}\left(\frac{x_{T}}{x_{t}}, e^{-\int_{t}^{T} r_{s} d s}\right)
\end{aligned}
$$

As usual in this area it is difficult to have an intuitive feeling for such covariance properties under $Q$; but under the physical measure, at least, it is unlikely that this covariance term vanishes.

\subsection{The model}

\subsubsection{Without exchange rate risk}

The model is based on the dynamics for the spot price of the underlying energy commodity, the term structure of futures convenience yield and the term structure of forward interest rates. This choice is explained by the experience from the HJM analysis, which shows that it is appropriate to initiate the building of the model for zero-coupon bond prices from the dynamics of the forward interest rates. Similarly, the futures prices are most appropriately modelled from the dynamics of the futures convenience yield. Because the objective of the analysis is to price derivatives we start the specification of the model directly under the equivalent $\mathbf{Q}$ measure.

The spot commodity price is assumed to follow the SDE

$$
S_{t}=S_{t_{0}}+\int_{t_{0}}^{t} S_{u} \mu_{S}(u) d u+\int_{t_{0}}^{t} S_{u} \sigma_{S}(u) \cdot d W_{u}^{\mathbf{Q}}
$$

where $\left(W_{t}^{\mathbf{Q}}\right)$ is a standard $d$-dimensional Wiener process. The family of SDEs for the continuously compounded futures convenience yields is given by

$$
\epsilon(t, s)=\epsilon\left(t_{0}, s\right)+\int_{t_{0}}^{t} \mu_{\epsilon}(u, s) d u+\int_{t_{0}}^{t} \sigma_{\epsilon}(u, s) \cdot d W_{u}^{\mathbf{Q}}
$$

and the family of SDEs for the continuously compounded forward interest rates is given by

$$
f(t, s)=f\left(t_{0}, s\right)+\int_{t_{0}}^{t} \mu_{f}(u, s) d u+\int_{t_{0}}^{t} \sigma_{f}(u, s) \cdot d W_{u}^{\mathbf{Q}}
$$


Any possible correlation between the three processes is specified through the diffusion terms. At this point of the analysis the drift and diffusion terms are not specified further, except from the fact that they must fulfill certain regularity conditions in order to ensure the existence of strong solutions to the SDEs. So, in the general case, stochastic/state dependent diffusion terms and correlation between the processes is possible.

Under the $\mathbf{Q}$ measure the drift terms are completely determined by the diffusion terms. This is one of the main lessons from the HJM methodology. More specifically, under $\mathbf{Q}$ we have that

$$
\mu_{S}(t)=r_{t}-\epsilon(t, t)=f(t, t)-\epsilon(t, t)
$$

Furthermore, from the HJM analysis we have that the drift of the continuously compounded forward interest rate process under $\mathbf{Q}$ is given by

$$
\mu_{f}(t, T)=\sigma_{f}(t, T) \cdot \int_{t}^{T} \sigma_{f}(t, v) d v
$$

Finally, in Appendix A of Miltersen and Schwartz (1998) it is shown that the drift of any of the continuously compounded futures convenience yield processes under $\mathbf{Q}$ is given by

$$
\mu_{\epsilon}(t, T)=\sigma_{f}(t, T) \cdot \int_{t}^{T} \sigma_{f}(t, v) d v+\left(\sigma_{f}(t, T)-\sigma_{\epsilon}(t, T)\right) \cdot\left(\sigma_{S}(t)+\int_{t}^{T}\left(\sigma_{f}(t, v)-\sigma_{\epsilon}(t, v)\right) d v\right.
$$

\subsubsection{With exchange rate risk}

With introduction of exchange rate risk the only element necessary to add is the dynamics of the exchange rate process $\left(x_{t}\right)$. Assume that it is governed by the following SDE under $\mathbf{Q}$

$$
x_{t}=x_{t_{0}}+\int_{t_{0}}^{t} x_{u} \mu_{x}(u) d u+\int_{t_{0}}^{t} x_{u} \sigma_{x}(u) \cdot d W_{u}^{\mathbf{Q}}
$$

where $\mu_{x}$ by a simple no-arbitrage argument is given as the difference in spot interest rates

$$
\mu_{x}=r_{t}-r_{t}^{*}
$$

The SDE for the domestically measured spot price $\left(S_{t}\right)$ is conceptually unchanged from the situation without exchange rate risk, i.e.

$$
S_{t}=S_{t_{0}}+\int_{t_{0}}^{t} S_{u} \mu_{S}(u) d u+\int_{t_{0}}^{t} S_{u} \sigma_{S}(u) \cdot d W_{u}^{\mathbf{Q}}
$$

However, both the drift term and the volatility term are different from the previous specification without exchange rate risk. The drift term will depend on $\mu_{x}$ as well the correlation between the foreign price and the exchange rate. As far as the pricing of derivatives is concerned this makes no difference. On the other hand, the volatility for the domestically measured spot price 
enters into option pricing formulas; it is now a sum of the foreign spot price volatility and the exchange rate volatility, i.e. $\sigma_{S}(u)=\sigma_{S^{*}}(u)+\sigma_{x}(u)$.

The processes for the convenience yields and the domestic forward interest rates are unchanged. There is no need to introduce a new process for the foreign forward interest rate, as we shall soon assume interest rates to be deterministic. The only other change from the situation without exchange rate risk is that the dimension of the Wiener process is possibly increased in order to incorporate the extra stochastic factor arising from the exchange rate.

\section{The basic model for energy options}

\subsection{Options on a single-delivery futures contract}

Our first obejctive is to price a strike- $K$ call option on one single-delivery futures contract at date $t_{0}$. The option expires at date $t>t_{0}$ and the price of the futures contract with expiry at date $t \leq T$ is given by $F(t, T)$. The pricing procedure involves a standard change of probability measure from $\mathbf{Q}$ to $\mathbf{Q}^{t}$, the $t$-forward measure with the price process for the $t$-maturity zero-coupon bond as numeraire process.

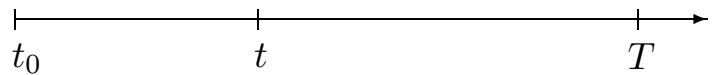

Figure 1: Time line showing the time of option pricing (current time) $t_{0}$, the option expiration time $t$ and the expiration time $T$ of the underlying futures contract.

Let $\beta(t)=\beta\left(t_{0}\right) \exp \left(\int_{t_{0}}^{t} r_{s} d s\right)$ denote the value of the money market account. Denote the price of the option by $C^{F}\left(t_{0}, t, T ; K\right)$. Then by change of numeraire calculations we get that

$$
\begin{aligned}
C^{F}\left(t_{0}, t, T ; K\right) & =\beta\left(t_{0}\right) \mathrm{E}_{t_{0}}^{\mathbf{Q}}\left[\frac{[F(t, T)-K]^{+}}{\beta(t)}\right]=\beta\left(t_{0}\right) \mathrm{E}_{t_{0}}^{\mathbf{Q}}\left[\frac{\left.(F(t, T)-K) \mathbf{1}_{\{F(t, T) \geq K\}}\right]}{\beta(t)}\right] \\
& =\beta\left(t_{0}\right) \mathrm{E}_{t_{0}}^{\mathbf{Q}}\left[\frac{F(t, T) \mathbf{1}_{\{F(t, T) \geq K\}}}{\beta(t)}\right]-\beta\left(t_{0}\right) K \mathrm{E}_{t_{0}}^{\mathbf{Q}}\left[\frac{\mathbf{1}_{\{F(t, T) \geq K\}}}{\beta(t)}\right] \\
& =P\left(t_{0}, t\right) \mathrm{E}_{t_{0}}^{\mathbf{Q}^{t}}\left[F(t, T) \mathbf{1}_{\{F(t, T) \geq K\}}\right]-P\left(t_{0}, t\right) K \mathrm{E}_{t_{0}}^{\mathbf{Q}^{t}\left[\mathbf{1}_{\{F(t, T) \geq K\}}\right]}
\end{aligned}
$$

This pricing equation holds in any case. But, in order to arrive at an operational closedform Black-Scholes like expression for the option price, we assume that the diffusion terms are deterministic functions. The problem then is to work out standard calculations with truncated lognormal distributions. From Appendix A in Miltersen and Schwartz (1998) we know that the dynamics for the futures price process, which is a martingale under $\mathbf{Q}$, is given by

$$
d F(u, T)=F(u, T) \widetilde{s}_{F}(u, T) \cdot d W_{u}^{\mathbf{Q}}
$$


where

$$
\widetilde{s}_{F}(u, T)=\sigma_{S}(u)+\int_{u}^{T}\left(\sigma_{f}(u, s)-\sigma_{\epsilon}(u, s)\right) d s
$$

The dynamics for the zero-coupon bond expiring at date $t$ is given by

$$
d P(u, t)=P(u, t) f(u, u) d u-P(u, t) s_{P}(u, t) d W_{u}^{\mathbf{Q}}
$$

where

$$
s_{P}(u, t)=\int_{u}^{t} \sigma_{f}(u, s) d s
$$

The dynamics of the futures price process under $\mathbf{Q}^{t}$ is found by a standard transformation, cf. e.g. Theorem 19.8 from Björk (1998):

$$
d F(u, T)=F(u, T)\left(-\widetilde{s}_{F}(u, T) \cdot s_{P}(u, t)\right) d u+F(u, T) \widetilde{s}_{F}(u, T) \cdot d W_{u}^{\mathbf{Q}^{t}}
$$

implying that

$$
F(u, T)=F\left(t_{0}, T\right) e^{-\int_{t_{0}}^{u} \widetilde{s}_{F}(v, T) \cdot s_{P}(v, t) d v-\frac{1}{2} \int_{t_{0}}^{u}\left\|\widetilde{s}_{F}(v, T)\right\|^{2} d v+\int_{t_{0}}^{u} \widetilde{s}_{F}(v, T) \cdot d W_{v}^{\mathbf{Q}^{t}}}
$$

For notational simplicity let

$$
\Sigma_{F P}=\int_{t_{0}}^{t} \widetilde{s}_{F}(v, T) \cdot s_{P}(v, t) d v
$$

and

$$
\widetilde{\Sigma}_{F}^{2}=\int_{t_{0}}^{t}\left\|\widetilde{s}_{F}(v, T)\right\|^{2} d v
$$

Now we are able to compute the pricing formula (3.1):

$$
\begin{aligned}
\mathrm{E}_{t_{0}}^{\mathbf{Q}^{t}}\left[1_{\{F(t, T) \geq K\}}\right] & =\mathbf{Q}^{t}\left(F\left(t_{0}, T\right) e^{-\Sigma_{F P}-\frac{1}{2} \widetilde{\Sigma}_{F}^{2}+\int_{t_{0}}^{t} \widetilde{s}_{F}(v, T) \cdot d W_{v}^{\mathbf{Q}^{t}}} \geq K\right) \\
& =\mathbf{Q}^{t}\left(-\int_{t_{0}}^{t} \widetilde{s}_{F}(v, T) \cdot d W_{v}^{\mathbf{Q}^{t}} \leq \log \left(\frac{F\left(t_{0}, T\right)}{K}\right)-\Sigma_{F P}-\frac{1}{2} \widetilde{\Sigma}_{F}^{2}\right) \\
& =\Phi\left(\frac{\log \left(\frac{F\left(t_{0}, T\right)}{K}\right)-\Sigma_{F P}-\frac{1}{2} \widetilde{\Sigma}_{F}^{2}}{\sqrt{\widetilde{\Sigma}_{F}^{2}}}\right)
\end{aligned}
$$

where $\Phi(\cdot)$ denotes the standard normal cumulative distribution function. Analogously, by standard calculations the first term is

$$
\begin{gathered}
P\left(t_{0}, t\right) \mathrm{E}_{t_{0}}^{\mathbf{Q}^{t}}\left[F(t, T) \mathbf{1}_{F(t, T) \geq K}\right]=P\left(t_{0}, t\right) F\left(t_{0}, T\right) \mathrm{E}_{t_{0}}^{\mathbf{Q}^{t}}\left[\frac{F(t, T)}{F\left(t_{0}, T\right)} \mathbf{1}_{\{F(t, T) \geq K\}}\right]= \\
P\left(t_{0}, t\right) F\left(t_{0}, T\right) \mathrm{E}_{t_{0}}^{\mathbf{Q}^{t}}\left[e^{-\Sigma_{F P}-\frac{1}{2} \widetilde{\Sigma}_{F}^{2}+\int_{t_{0}}^{t} \widetilde{s}_{F}(v, T) \cdot d W_{v}^{\mathbf{Q}^{t}}} \mathbf{1}_{\{F(t, T) \geq K\}}\right]= \\
P\left(t_{0}, t\right) F\left(t_{0}, T\right) e^{-\Sigma_{F P}} \Phi\left(\frac{\log \left(\frac{F\left(t_{0}, T\right)}{K}\right)-\Sigma_{F P}+\frac{1}{2} \widetilde{\Sigma}_{F}^{2}}{\sqrt{\widetilde{\Sigma}_{F}^{2}}}\right)
\end{gathered}
$$


Collecting terms the final result is

$$
\begin{aligned}
C^{F}\left(t_{0}, t, T ; K\right) & =P\left(t_{0}, t\right) F\left(t_{0}, T\right) e^{-\Sigma_{F P}} \Phi\left(\frac{\log \left(\frac{F\left(t_{0}, T\right)}{K}\right)-\Sigma_{F P}+\frac{1}{2} \widetilde{\Sigma}_{F}^{2}}{\sqrt{\widetilde{\Sigma}_{F}^{2}}}\right) \\
& -P\left(t_{0}, t\right) K \Phi\left(\frac{\log \left(\frac{F\left(t_{0}, T\right)}{K}\right)-\Sigma_{F P}-\frac{1}{2} \widetilde{\Sigma}_{F}^{2}}{\sqrt{\widetilde{\Sigma}_{F}^{2}}}\right)
\end{aligned}
$$

This provides a closed-form expression for the price at date $t_{0}$ of a strike- $K$ call with maturity date $t \geq t_{0}$ written on a futures contract with maturity date $T \geq t$. In Miltersen and Schwartz (1998), Appendix B, the authors derive the price equation for a similar call option, but in a different way without explicitly introducing the change of measure from $\mathbf{Q}$ to $\mathbf{Q}^{t}$. The procedure used here is considerably shorter and simpler.

An almost identical analysis would show that the price $P^{F}\left(t_{0}, t, T ; K\right)$ at date $t_{0}$ of a similar strike- $K$ put option with maturity date $t \geq t_{0}$ on a futures contract with maturity date $T \geq t$ is given by

$$
\begin{aligned}
P^{F}\left(t_{0}, t, T ; K\right)= & P\left(t_{0}, t\right) K \Phi\left(\frac{\log \left(\frac{F\left(t_{0}, T\right)}{K}\right)-\Sigma_{F P}-\frac{1}{2} \widetilde{\Sigma}_{F}^{2}}{-\sqrt{\widetilde{\Sigma}_{F}^{2}}}\right) \\
& -P\left(t_{0}, t\right) F\left(t_{0}, T\right) e^{-\Sigma_{F P}} \Phi\left(\frac{\log \left(\frac{F\left(t_{0}, T\right)}{K}\right)-\Sigma_{F P}+\frac{1}{2} \widetilde{\Sigma}_{F}^{2}}{-\sqrt{\widetilde{\Sigma}_{F}^{2}}}\right)
\end{aligned}
$$

Relevant sensitivity parameters, i.e. the Greeks like delta, gamma etc., can now be found by standard methods. Observe from (3.7) that the process $F(u, T) e^{\int_{t_{0}}^{u} \widetilde{s}_{F}(v, T) \cdot s_{P}(v, t) d v}$ is a $Q^{t}$-martingale:

$$
F(u, T) e^{\int_{t_{0}}^{u} \widetilde{s}_{F}(v, T) \cdot s_{P}(v, t) d v}=F\left(t_{0}, T\right) e^{-\frac{1}{2} \int_{t_{0}}^{u}\left\|\widetilde{s}_{F}(v, T)\right\|^{2} d v+\int_{t_{0}}^{u} \widetilde{s}_{F}(v, T) \cdot d W_{v}^{\mathbf{Q}^{t}}}
$$

Hence, the result in (3.1) can be restated as

$$
\left.C^{F}\left(t_{0}, t, T ; K\right)=P\left(t_{0}, t\right) F\left(t_{0}, T\right) e^{-\Sigma_{F P}} \mathrm{E}_{t_{0}}^{\mathbf{Q}^{T}}\left[\mathbf{1}_{\{F(t, T) \geq K\}}\right]-P\left(t_{0}, t\right) K \mathrm{E}_{t_{0}} \mathbf{Q}_{\{F(t, T) \geq K\}}\right]
$$

where the $\mathbf{T}$-futures measure $Q^{T}$ is defined from $Q^{t}$ by

$$
\left.\frac{d Q^{T}}{d Q^{t}}\right|_{\mathcal{F}_{t_{0}}}=e^{-\frac{1}{2} \int_{t_{0}}^{t}\left\|\widetilde{s}_{F}(v, T)\right\|^{2} d v+\int_{t_{0}}^{t} \widetilde{s}_{F}(v, T) \cdot d W_{v}^{\mathbf{Q}^{t}}}
$$

\subsection{Deterministic interest rates and exchange rate risk}

If interest rates are assumed to be deterministic, i.e. $\sigma_{f}(u, s)=0$ for all $u, s$, the call price $(3.12)$ simplifies to

$$
C^{F}\left(t_{0}, t, T ; K\right)=P\left(t_{0}, t\right)\left(F\left(t_{0}, T\right) \Phi\left(\frac{\log \left(\frac{F\left(t_{0}, T\right)}{K}\right)+\frac{1}{2} \widetilde{\Sigma}_{F}^{2}}{\sqrt{\widetilde{\Sigma}_{F}^{2}}}\right)-K \Phi\left(\frac{\log \left(\frac{F\left(t_{0}, T\right)}{K}\right)-\frac{1}{2} \widetilde{\Sigma}_{F}^{2}}{\sqrt{\widetilde{\Sigma}_{F}^{2}}}\right)\right)
$$


When introducing the two country/currency case with exchange rate risk, the formula has to be modified such that the foreign price of the futures contract is expressed in the domestic currency and the volatility of the futures contract, seen from the domestic country, now incorporates the exchange rate risk. $K$ is, of course, expressed in the domestic currency too. This gives the following final pricing formula.

$$
C^{F}\left(t_{0}, t, T ; K\right)=P\left(t_{0}, t\right)\left(F\left(t_{0}, T\right) \Phi\left(d_{1}\right)-K \Phi\left(d_{2}\right)\right)
$$

where

$$
\begin{aligned}
& F\left(t_{0}, T\right)=x_{t_{0}} F^{*}\left(t_{0}, T\right) e^{\int_{t_{0}}^{T}\left(f\left(t_{0}, s\right)-f^{*}\left(t_{0}, s\right)\right) d s}=x_{t_{0}} F^{*}\left(t_{0}, T\right) e^{\int_{t_{0}}^{T}\left(r_{s}-r_{s}^{*}\right) d s} \\
& s_{F}(u, T)=\sigma_{S}(u)-\int_{u}^{T} \sigma_{\epsilon}(u, s) d s=\sigma_{S^{*}}(u)+\sigma_{x}(u)-\int_{u}^{T} \sigma_{\epsilon}(u, s) d s \\
& \Sigma_{F}^{2}=\int_{t_{0}}^{t}\left\|s_{F}(u, T)\right\|^{2} d u \\
& d_{1}=\frac{\log \left(\frac{F\left(t_{0}, T\right)}{K}\right)+\frac{1}{2} \Sigma_{F}^{2}}{\sqrt{\Sigma_{F}^{2}}}, \quad d_{2}=d_{1}-\sqrt{\Sigma_{F}^{2}}
\end{aligned}
$$

The pricing formula for the corresponding put option is given by

$$
P^{F}\left(t_{0}, t, T ; K\right)=P\left(t_{0}, t\right)\left(K \Phi\left(-d_{2}\right)-F\left(t_{0}, T\right) \Phi\left(-d_{1}\right)\right)
$$

$F^{*}\left(t_{0}, T\right)$ denotes the futures price expressed in foreign currency, and $f^{*}\left(t_{0}, s\right)$ and $r^{*}$ for $t_{0} \leq s \leq$ $\bar{T}$ denote the foreign forward and spot interest rate, respectively. Note that future spot interest rates are identical to forward rates because interest rates are deterministic. Moreover, futures prices and forward prices coincide in both countries and are related to each other through the forward exchange rate, cf. Theorem 1.

The assumption of deterministic interest rates implies that the pricing formulas for options are identical, when the options are written on a forward contract similar to the futures contract.

\subsection{Options on a portfolio of futures}

The pricing technique for options on single-delivery futures from the previous subsection makes it possible to price an option on a portfolio of futures contracts. Define the price of the whole contract with expiry at date $\bar{T}$ as

$$
F(t, \bar{T})=\sum_{i=1}^{n} \alpha_{i} F\left(t, T_{i}\right)
$$

where $t \leq T_{i} \leq T_{i+1} \leq \bar{T}$ for all $i=1, \ldots, n-1$ and $T_{n}=\bar{T}$. The $\alpha_{i}$ 's are numbers that indicate how many single-delivery contracts the investor holds for every delivery date. In the case, where the $\alpha_{i}$ 's are all equal and the $T_{i}$ 's equidistant, it means that the portfolio is a contract for constant delivery throughout the period $\left[T_{1}, T_{n}\right]$. Figure 2 illustrates the location of the relevant points in time. 


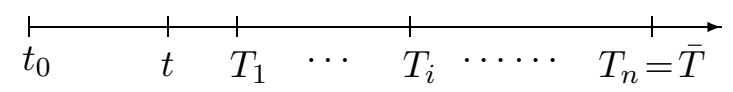

Figure 2: Time line showing the time of option pricing (current time) $t_{0}$, the option expiration time $t$ and the expiration times $\left\{T_{i}\right\}_{\{1 \leq i \leq n\}}$ of the underlying single-delivery futures contracts.

Denote the price of the option by $C^{F}\left(t_{0}, t, \bar{T}\right)$. Analogous to the pricing relation developed above we have that

$$
\begin{aligned}
& C^{F}\left(t_{0}, t, \bar{T} ; K\right)=\beta\left(t_{0}\right) \mathrm{E}_{t_{0}}^{\mathbf{Q}}\left[\frac{[F(t, \bar{T})-K]^{+}}{\beta(t)}\right]=\beta\left(t_{0}\right) \mathrm{E}_{t_{0}}^{\mathbf{Q}}\left[\frac{(F(t, \bar{T})-K) \mathbf{1}_{\{F(t, \bar{T}) \geq K\}}}{\beta(t)}\right] \\
& =\beta\left(t_{0}\right) \mathrm{E}_{t_{0}}^{\mathbf{Q}}\left[\frac{F(t, \bar{T}) \mathbf{1}_{\{F(t, \bar{T}) \geq K\}}}{\beta(t)}\right]-\beta\left(t_{0}\right) K \mathrm{E}_{t_{0}}^{\mathbf{Q}}\left[\frac{\mathbf{1}_{\{F(t, \bar{T}) \geq K\}}}{\beta(t)}\right] \\
& =P\left(t_{0}, t\right) \mathrm{E}_{t_{0}}^{\mathbf{Q}^{t}}\left[F(t, \bar{T}) \mathbf{1}_{\{F(t, \bar{T}) \geq K\}}\right]-P\left(t_{0}, t\right) K \mathrm{E}_{t_{0}}^{\mathbf{Q}^{t}}\left[\mathbf{1}_{\{F(t, \bar{T}) \geq K\}}\right] \\
& =P\left(t_{0}, t\right) \sum_{i=1}^{n} \alpha_{i} F\left(t_{0}, T_{i}\right) \mathrm{E}_{t_{0}}^{\mathbf{Q}^{T_{i}}}\left[\mathbf{1}_{\{F(t, \bar{T}) \geq K\}}\right]-P(0, t) K \mathrm{E}_{t_{0}}^{\mathbf{Q}^{t}}\left[\mathbf{1}_{\{F(t, \bar{T}) \geq K\}}\right]
\end{aligned}
$$

So in principle we have found the price of the option. In order to make this pricing equation applicable in practice, it is necessary to find the probabilities of the event $\{F(t, \bar{T}) \geq K\}$ under the $\mathbf{Q}^{t}$ and $\mathbf{Q}^{T_{i}}$ measures. However, it is not obvious how to find these, because $F(t, \bar{T})$ is a sum of $\log$-normally distributed variables, so when $n \geq 2$ it is not log-normally distributed itself.

Jamshidian (1989) and Longstaff (1993) show how to cope with this problem and obtain a closedform solution when pricing European coupon bond options in the Vasiček and CIR one-factor interest rate models, respectively. The Jamshidian approach can be extended to all one-factor models, where the relative price volatility $\sigma(t, T)$ at time $t$ of a zero-coupon bond with maturity date $T$ can be factored as $\sigma(t, T)=(g(T)-g(t)) h(t)$, where $g$ and $h$ satisfy certain regularity conditions. This is known as the condition under which the process for the short term rate of interest is Markovian, cf. Carverhill (1994). ${ }^{3}$ The basic methodology rests on the perception of the coupon bond as a portfolio of zero-coupon bonds.

When it comes to bond option pricing in multi-factor models, several models offer a closed-form solution for the price of European options on zero-coupon bonds. All multi-factor exponential affine term structure models offer closed-form solutions for zero-coupon bond option prices. However, no closed-form solutions are known for European coupon bond option prices in multifactor models. In order to cope with this problem, Munk (1999) suggests how to approximate

\footnotetext{
${ }^{3}$ More precisely, $g$ is a $\mathcal{C}^{1}\left(\mathbb{R}, \mathbb{R}_{+}\right)$function and $h$ is a $\mathcal{C}\left(\mathbb{R}, \mathbb{R}_{+}\right)$function.
} 
the price of a European coupon bond option with a fast and precise numerical method. The idea is to approximate the coupon bond option price by a multiple of the price of a European option on a zero-coupon bond with a time to maturity equal to the stochastic duration of the coupon bond.

We shall apply this approach when pricing options on portfolios of futures and look into the details in the next section. A single-delivery futures is analogous to a zero-coupon bond; hence, a portfolio of single-delivery futures is analogous to a coupon bond. We approximate the option price by a multiple of a constant $\varphi$ and the price of a European option on a single-delivery futures with a time to maturity equal to the so-called stochastic duration of the futures portfolio, and a strike equal to the strike of the futures portfolio option divided by $\varphi$.

An alternative approach to pricing European coupon-bond options has recently been proposed in Singleton and Umantsev (2002) for the case of affine term structure models, i.e. where bond prices are affine functions of the state variables. The idea is to approximate the option's optimal exercise boundary by a hyperplane in $\mathbb{R}^{m}$, where $m$ equals the number of factors in the model. This approximation makes it possible to calculate the probability of the bond being in the money at the option expiration date under the relevant probability measures. This reduces to calculating the sum of $n+1$ probabilities of a zero-coupon bond being in the money, where $n$ equals the number of remaining bond payments after the option's expiration date.

Knowledge of the conditional characteristic function for the state variables and the fact that the zero-coupon bond prices are exponential affine functions of the state variables is sufficient to derive closed form solutions, cf. e.g. section 2 in Singleton and Umantsev (2002). Longstaff and Schwartz (1992) is a two state variable example of this. All relevant option sensitivity parameters can in principle be calculated along the same lines.

Examples provided by Singleton and Umantsev (2002) indicate that this approach is more precise than the stochastic duration approach and that the pricing error is independent of the moneyness of the option. However, this precision comes at a cost. The approach is much more complicated to implement, and the calculations are more time consuming. Calculating the price of a bond option with only two remaining payments at option expiry takes almost six times longer than using the stochastic duration approach according to an example provided by Singleton and Umantsev (1.42 seconds compared to 0.24 seconds). As the computing time increases linearly in the number of remaining payments, which in our case corresponds to delivery times and can be much higher than the number of coupon payments usually found in the bond market, one can easily imaging a situation where this approach spends unacceptable long time to perform the calculation compared to the stochastic duration approach. Thus, despite its theoretical beauty and the higher degree of precision, we shall not deal further with this approach in the paper. 


\subsubsection{Pricing the option by approximation}

Given that the pricing is considerably easier for a single-delivery futures one could consider different ways of approximating the dynamics of the futures portfolio by the dynamics of a single-delivery futures with maturity $T$. This could be in a myopic sense by replicating the infinitesimal volatility term of the portfolio, but it could equally well be an attempt to replicate some of the distributional characteristics of the portfolio at the expiration date $t$ of the option.

We shall stick to the nomenclature in Munk (1999) and denote the relative diffusion coefficients of the futures price process as $s_{F_{j}}(u, T), j=1, \ldots, d$, for factor sensitivities. So the $j$ 'th factor sensitivity is a relative futures price diffusion coefficient with respect to one single source of uncertainty, namely the $j$ 'th component of the $d$-dimensional process $\left(W_{u}^{\mathbf{Q}}\right)$. Note that in most cases when the text reads $s_{F_{j}}(u, T)$ it is understood that it is for an arbitrary $j \in\{1, \ldots, d\}$. We rewrite the dynamics of the single-delivery futures price in a way that emphasizes the dependency of a $d$-dimensional Wiener process

$$
d F(u, T)=F(u, T) s_{F}(u, T) \cdot d W_{u}^{\mathbf{Q}}=F(u, T) \sum_{j=1}^{d} s_{F_{j}}(u, T) d W_{j}^{\mathbf{Q}}(u)
$$

where $s_{F}(u, T)=\left(s_{F_{1}}(u, T), \cdots, s_{F_{d}}(u, T)\right)^{T}$ and $W_{u}^{\mathbf{Q}}=\left(W_{1}^{\mathbf{Q}}(u), \cdots, W_{d}^{\mathbf{Q}}(u)\right)^{T}$ with $(\cdot, \cdots, \cdot)^{T}$ denoting the transpose of a row vector. Similarly the dynamics for the portfolio position is given by

$$
\begin{aligned}
d F(u, \bar{T}) & =\sum_{i=1}^{n} \alpha_{i} d F\left(u, T_{i}\right) \\
& =\sum_{i=1}^{n} \alpha_{i} F\left(u, T_{i}\right) \sum_{j=1}^{d} s_{F_{j}}\left(u, T_{i}\right) d W_{j}^{\mathbf{Q}}(u) \\
& =F(u, \bar{T})\left(\sum_{i=1}^{n} w\left(u, T_{i}\right) \sum_{j=1}^{d} s_{F_{j}}\left(u, T_{i}\right) d W_{j}^{\mathbf{Q}}(u)\right) \\
& =F(u, \bar{T})\left(\sum_{i=1}^{n} \sum_{j=1}^{d} w\left(u, T_{i}\right) s_{F_{j}}\left(u, T_{i}\right) d W_{j}^{\mathbf{Q}}(u)\right)
\end{aligned}
$$

where $w\left(u, T_{i}\right)$ are portfolio weights given by $w\left(u, T_{i}\right)=\frac{\alpha_{i} F\left(u, T_{i}\right)}{\sum_{i=1}^{n} \alpha_{i} F\left(u, T_{i}\right)}=\frac{\alpha_{i} F\left(u, T_{i}\right)}{F(u, \bar{T})}$.

The idea behind the approximation of a portfolio option price is as follows. Let $C^{F}\left(t_{0}, t, s ; K\right)$ be the price at time $t_{0}$ of a strike- $K$ European call option maturing at time $t$ on a single-delivery futures maturing at time $s$, where $t_{0} \leq t \leq s$. And let $C^{F}\left(t_{0}, t, \bar{T} ; K\right)$ be the price at time $t_{0}$ of a strike- $K$ European call option maturing at time $t$ on a futures portfolio maturing at time $\bar{T}$, where $t_{0} \leq t \leq \bar{T}$. Let $F\left(t_{0}, \bar{T}\right)=\sum_{i=1}^{n} \alpha_{i} F\left(t_{0}, T_{i}\right)$ denote the price of the futures portfolio at time $t_{0}$, where $t_{0} \leq t \leq T_{i} \leq T_{i+1}$ for all $i=1, \ldots, n-1$ and $T_{n}=\bar{T}$. The approximation is then given by

$$
C^{F}\left(t_{0}, t, \bar{T} ; K\right) \approx C_{\text {app }}^{F}\left(t_{0}, t, \bar{T} ; K\right) \equiv \varphi C^{F}\left(t_{0}, t, T ; \frac{K}{\varphi}\right)
$$


where $T \in[t, \bar{T}]$ is some chosen maturity of an approximating single-delivery futures and the scaling factor $\varphi$ is given by

$$
\varphi=\frac{F\left(t_{0}, \bar{T}\right)}{F\left(t_{0}, T\right)}
$$

The approximation for a similar put option on the futures portfolio is given by

$$
P^{F}\left(t_{0}, t, \bar{T} ; K\right) \approx P_{\mathrm{app}}^{F}\left(t_{0}, t, \bar{T} ; K\right) \equiv \varphi P^{F}\left(t_{0}, t, T ; \frac{K}{\varphi}\right)
$$

For an arbitrary maturity date $T$ of the approximating single-delivery futures the approximation error $\epsilon^{F}(T)$ in the call case can be evaluated under the $T$-futures measure $\mathbf{Q}^{T}$ with the $(F(u, T))$ process as numeraire process. The case of a put option is similar. Recall that all gain processes in the economy as well as futures price processes relative to the numeraire process $(F(u, T))$ are $\mathbf{Q}^{T}$-martingales. Then

$$
\begin{aligned}
\epsilon^{F}(T) & =F\left(t_{0}, T\right) \mathrm{E}_{t_{0}}^{\mathbf{Q}^{T}}\left[\frac{\max \{F(t, \bar{T})-K, 0\}}{F(t, T)}\right] \\
& -\frac{F\left(t_{0}, \bar{T}\right)}{F\left(t_{0}, T\right)} F\left(t_{0}, T\right) \mathrm{E}_{t_{0}}^{\mathbf{Q}^{T}}\left[\frac{\max \left\{F(t, T)-K \frac{F\left(t_{0}, T\right)}{F\left(t_{0}, \bar{T}\right)}, 0\right\}}{F(t, T)}\right] \\
& =F\left(t_{0}, T\right) \mathrm{E}_{t_{0}}^{\mathbf{Q}^{T}}\left[\max \left\{\frac{F(t, \bar{T})}{F(t, T)}-\frac{K}{F(t, T)}, 0\right\}-\max \left\{\frac{F\left(t_{0}, \bar{T}\right)}{F\left(t_{0}, T\right)}-\frac{K}{F(t, T)}, 0\right\}\right]
\end{aligned}
$$

where

$$
\mathrm{E}_{t_{0}}^{\mathbf{Q}^{T}}\left[\frac{F(t, \bar{T})}{F(t, T)}\right]=\frac{F\left(t_{0}, \bar{T}\right)}{F\left(t_{0}, T\right)}
$$

and

$$
\mathrm{E}_{t_{0}}^{\mathbf{Q}^{T}}\left[\frac{K}{F(t, T)}\right]=\frac{K}{F\left(t_{0}, T\right)},
$$

For a call option deeply in the money, both maximum terms are given by the first (non-zero) argument by a probability close to one, so by equation (3.29) we see that the difference between the two terms and hence the approximation error $\epsilon^{F}(T)$ is close to zero. For call options deeply out of the money, both maximum terms are zero with a probability close to one, so similarly $\epsilon^{F}(T)$ is close to zero.

Only when one of the maximum terms yields zero and the other one non-zero $\epsilon^{F}(T)$ is affected more substantially. This is the case, when $\frac{K}{F(t, T)}$ is between $\frac{F(t, \bar{T})}{F(t, T)}$ and $\frac{F\left(t_{0}, \bar{T}\right)}{F\left(t_{0}, T\right)}$ at time $t$. Therefore, to keep the error $\epsilon^{F}(T)$ on a minimal level, $T$ should be chosen such that $\frac{F(t, \bar{T})}{F(t, T)}$ stays close to $\frac{F\left(t_{0}, \bar{T}\right)}{F\left(t_{0}, T\right)}$.

\subsubsection{Stochastic duration}

For a futures portfolio we shall define the stochastic duration $\delta^{F}(u)$ at time $u$ as the time to maturity of the single-delivery futures with the same relative price volatility as the portfolio. 
I.e., $\delta^{F}(u)$ is defined by the equation

$$
\sum_{j=1}^{d} s_{F_{j}}\left(u, u+\delta^{F}(u)\right)^{2}=\sum_{j=1}^{d}\left(\sum_{i=1}^{n} w\left(u, T_{i}\right) s_{F_{j}}\left(u, T_{i}\right)\right)^{2}
$$

The usual concept of duration in fixed income analysis is a risk measure gauging the entire relative price reaction to a change in the yield - or in more general models the entire relative price reaction to a change in some common exogenous variable. The present definition relates only to the volatility term. However, it shares a basic property with the usual duration measure; the definition implies that the stochastic duration of a single-delivery futures equals its time to maturity just as the duration of a zero-coupon bond is its time to maturity.

By the very definition of the stochastic duration choosing $T=t_{0}+\delta^{F}\left(t_{0}\right)$ assures that the relative changes in $F(\cdot, T)$ and $F(\cdot, \bar{T})$ at time $t_{0}$ are close to each other over the next infinitesimal time interval. Hence, the approximation is a myopic one, and whether they are actually equal depends on the size of the drift of the two price processes under $\mathbf{Q}^{T}$. On the other hand, in many models it is an easy to compute measure and as will be shown subsequently it has a reasonably good fit when compared to option prices found by Monte Carlo simulation.

An alternative choice ${ }^{4}$ is to measure the cumulative variance of the portfolio over the entire remaining lifetime of the option, i.e. over the interval $\left[t_{0}, t\right]$, and find a representative single futures that has the same accumulated variance over this interval. Based on these considerations we define an alternative stochastic duration $\delta^{F_{A}}\left(t_{0}\right)$ for the portfolio from the following (approximate) equality:

$$
\begin{aligned}
\int_{t_{0}}^{t} \sum_{j=1}^{d} s_{F_{j}}\left(u, t_{0}+\delta^{F_{A}}\left(t_{0}\right)\right)^{2} d u & =\int_{t_{0}}^{t} \sum_{j=1}^{d}\left(\sum_{i=1}^{n} w\left(t_{0}, T_{i}\right) s_{F_{j}}\left(u, T_{i}\right)\right)^{2} d u \\
& \approx E^{Q}\left[\int_{t_{0}}^{t} \sum_{j=1}^{d}\left(\sum_{i=1}^{n} w\left(u, T_{i}\right) s_{F_{j}}\left(u, T_{i}\right)\right)^{2} d u \mid \mathcal{F}_{t}\right]
\end{aligned}
$$

In section 5.1 we report on Monte Carlo simulations and compare the pricing errors with this measure to the myopic stochastic duration.

\subsubsection{Basic properties of stochastic duration}

We omit most details in this section; in most cases they can be found in section 1.2 in Munk (1999) in the case of coupon bonds. The stochastic duration measure has the following proper-

\footnotetext{
${ }^{4}$ Yet another candidate was suggested in Munk (1999), namely to incorporate explicitly the drift and look for $T^{\prime}=\operatorname{argmin}_{T} \operatorname{Var}_{t_{0}}^{\mathbf{Q}^{T}}\left(\left.\left\{\frac{\text { drift+diffusion of } F(u, T)}{F(u, T)}-\frac{\text { drift+diffusion of } F(u, \bar{T})}{F(u, \bar{T})}\right\}\right|_{u=t_{0}}\right)$. As Munk (1999) argues, $T^{\prime}$ and $t_{0}+\delta^{F}\left(t_{0}\right)$ will be equal for all one-factor models, whereas they may differ in multi-factor models. However, according to the numerical results reported in Munk (1999) for two-factor models, including a two-factor HJM model, this did not improve the pricing accuracy.
} 
ties, most of them obvious or very simply proven:

- If the factor sensitivities $s_{F_{j}}(u, T)$ are either positive and increasing in $T$ or negative and decreasing in $T$, then $\sum_{j=1}^{d} s_{F_{j}}(u, T)^{2}$ is increasing in $T$. If the factor sensitivities $s_{F_{j}}(u, T)$ are either positive and decreasing or negative and increasing in $T$, then $\sum_{j=1}^{d} s_{F_{j}}(u, T)^{2}$ is decreasing in $T$.

- If the factor sensitivities $s_{F_{j}}(u, T)$ are either all increasing or all decreasing in $T$ for all $j$ and at least one of them is strictly increasing respectively decreasing, then a unique solution $\delta^{F}(u)$ to equation (3.31) exists in the interval $T_{1} \leq u+\delta^{F}(u) \leq T_{n}$.

There is also a parallel to the well-known Fisher-Weil duration applied in the analysis of coupon bonds. The Fisher-Weil duration is a weighted average of the times to maturity of the bond's payments, weighted with the portfolio weights of the individual payments when calculated in accordance with the existing zero-coupon term structure. In the context of futures the duration measure is similar, but we shall call it the Fisher-Weil futures duration.

Definition 1 The Fisher-Weil futures duration $\delta_{F W}^{F}$ is defined by

$$
\delta_{F W}^{F}=\frac{\sum_{i=1}^{n} \alpha_{i} F\left(u, T_{i}\right)\left(T_{i}-u\right)}{\sum_{i=1}^{n} \alpha_{i} F\left(u, T_{i}\right)}=\sum_{i=1}^{n} w\left(u, T_{i}\right)\left(T_{i}-u\right)=\sum_{i=1}^{n} w\left(u, T_{i}\right) T_{i}-u
$$

where $w\left(u, T_{i}\right)=\frac{\alpha_{i} F\left(u, T_{i}\right)}{\sum_{i=1}^{n} \alpha_{i} F\left(u, T_{i}\right)}$ are positive weights and $\sum_{i=1}^{n} w\left(u, T_{i}\right)=1$.

The following proposition deals with a situation, where the stochastic duration and the FisherWeil futures duration are identical. This is the case for a special class of models, namely models with so-called linear factor sensitivities, i.e. when

$$
s_{F_{j}}(u, T)=(T-u) b_{j}(u) \forall j
$$

for some smooth maturity-independent functions $b_{j}$ for all $j$.

Proposition 1 If the factor sensitivities $s_{F_{j}}(u, T)$ are linear for all $j$, then the stochastic duration $\delta^{F}(u)$ is uniquely determined and identical with the Fisher-Weil futures duration $\delta_{F W}^{F}(u)$.

Proof Linear factor sensitivities imply $\sum_{i=1}^{n} w\left(u, T_{i}\right) s_{F_{j}}\left(u, T_{i}\right)=s_{F_{j}}\left(u, \sum_{i=1}^{n} w\left(u, T_{i}\right) T_{i}\right)$ for all $j$. Hence, $\sum_{j=1}^{d}\left(\sum_{i=1}^{n} w\left(u, T_{i}\right) s_{F_{j}}\left(u, T_{i}\right)\right)^{2}=\sum_{j=1}^{d}\left(s_{F_{j}}\left(u, \sum_{i=1}^{n} w\left(u, T_{i}\right) T_{i}\right)\right)^{2}$. By the very definition of the stochastic duration $\delta^{F}$ and the Fisher-Weil futures duration $\delta_{F W}^{F}$ the LHS of the last expression equals $\sum_{j=1}^{d} s_{F_{j}}\left(u, u+\delta^{F}(u)\right)^{2}$, while the RHS is equal to $\sum_{j=1}^{d}\left(s_{F_{j}}\left(u, u+\delta_{F W}^{F}(u)\right)\right)^{2}$. Furthermore, the LHS is an increasing function in the variable 
$\delta^{F}(u)$, which is to be determined; the partial derivative is $2 \sum_{j=1}^{d} \delta^{F}(u) b_{j}(u)^{2}$ and hence positive. Consequently $\delta^{F}(u)=\delta_{F W}^{F}(u)$.

Thus, in the special case where all factor sensitivities are linear, the simple Fisher-Weil futures duration is indeed a valid risk measure for the futures portfolio $F(u, \bar{T})$ and is identical to the risk measure implied by the stochastic duration. Conversely, for one-factor models where the factor sensitivity has the same sign for all maturities the implication in the proof of proposition 1 turns into a biimplication and the converse to the proposition is true: If the stochastic duration and the Fisher-Weil futures duration are equal, then the factor sensitivity is linear. For multifactor models it is not so straightforward and the reverse of proposition 1 is not true in general. Stronger assumptions on the factor sensitivity are needed for this.

\subsection{Options on flow forward contracts}

\subsubsection{Pricing flow forward contracts}

Flow forward contracts can be regarded as a finite sum of $n$ (properly discounted) single-delivery forwards. The discounting is done in order to take into consideration when the forward payments are actually paid. Let $t$ be current time and the maturity dates of the single-delivery forwards be $t \leq T_{i} \leq T_{i+1} \leq \bar{T}$ for all $i=1, \ldots, n-1$ and $T_{n}=\bar{T}$. If the flow forward is a contract for $\frac{1}{n}$ unit of the energy commodity per sub-period, i.e. one unit over the whole period, and the whole forward payment is done upfront, then the value of the flow forwards is simply $\frac{1}{n} \sum_{i=1}^{n} G\left(t, T_{i}\right)$. Inspired by the payment structure at the Nordic power forward market, where a flow forward contract is settled through daily payments, we investigate the case, where the forward price $G(t, \bar{T})$ of the entire flow contract is paid sequentially as a constant fraction of $G(t, \bar{T}) / n$ during the delivery period $\left[T_{1}, T_{n}\right]$. By a simple discounting argument one gets that

$$
\frac{G(t, \bar{T})}{n}=\sum_{i=1}^{n} \frac{e^{-\int_{t}^{T_{i}} f(t, s) d s}}{\sum_{i=1}^{n} e^{-\int_{t}^{T_{i}} f(t, s) d s}} \frac{G\left(t, T_{i}\right)}{n}
$$

Or

$$
G(t, \bar{T})=\sum_{i=1}^{n} \gamma_{i} G\left(t, T_{i}\right)
$$

where the $\gamma_{i}$ 's are positive weights given by

$$
\gamma_{i}=\frac{e^{-\int_{t}^{T_{i}} f(t, s) d s}}{\sum_{i=1}^{n} e^{-\int_{t}^{T_{i}} f(t, s) d s}}
$$

So the forward price $G(t, \bar{T})$ may be interpreted as a weighted average of single-delivery forward prices over the delivery period $\left[T_{1}, T_{n}\right]$, where the weights are determined by a discounting reflecting the term structure of interest rates and the difference in delivery dates of the singledelivery contracts. Note that given the assumption of deterministic interest rates, the $\gamma_{i}$ 's are themselves deterministic. 


\subsubsection{The stochastic duration of a flow forward}

From the preceding discussion we have seen that the $\gamma_{i}$ 's are deterministic throughout the period of interest $\left[t_{0}, t\right]$. This allows us to define the stochastic duration $\delta^{G}(u)$ of a flow forward at time $u$ similar to the stochastic duration for a futures portfolio, i.e. as the time to maturity of the single-delivery forward with the same relative price volatility as the flow forward. This means that $\delta^{G}(u)$ is defined by the equation

$$
\sum_{j=1}^{d} s_{F_{j}}\left(u, u+\delta^{G}(u)\right)^{2}=\sum_{j=1}^{d}\left(\sum_{i=1}^{n} v\left(u, T_{i}\right) s_{F_{j}}\left(u, T_{i}\right)\right)^{2}
$$

where

$$
v\left(u, T_{i}\right)=\frac{\gamma_{i} G\left(u, T_{i}\right)}{\sum_{i=1}^{n} \gamma_{i} G\left(u, T_{i}\right)}
$$

We see that the only difference between the two stochastic durations $\delta^{G}$ and $\delta^{F}$ comes via differences in the portfolio weights - the $v$ 's and the $w$ 's, respectively. Consequently, the properties of $\delta^{G}$ are as described for $\delta^{F}$ in section 3.3.3.

\subsubsection{Pricing the flow option}

The price approximation for the flow forward option follows the same line as for the option on a futures portfolio. Let $C^{G}\left(t_{0}, t, T ; K\right)$ be the price at time $t_{0}$ of a strike- $K$ European call option maturing at time $t$ on a single-delivery forward maturing at time $T$, where $t_{0} \leq t \leq T$. And let $C^{G}\left(t_{0}, t, \bar{T} ; K\right)$ be the price at time $t_{0}$ of a strike- $K$ European call option maturing at time $t$ on a flow forward maturing at time $\bar{T}$, where $t_{0} \leq t \leq \bar{T}$. Let $G\left(t_{0} \bar{T}\right)=\sum_{i=1}^{n} \gamma_{i} G\left(t_{0}, T_{i}\right)$ denote the price of the flow forward at time $t_{0}$, where $t_{0} \leq t \leq T_{i} \leq T_{i+1}$ for all $i=1, \ldots, n-1$ and $T_{n}=\bar{T}$. The approximation is given by

$$
C^{G}\left(t_{0}, t, \bar{T} ; K\right) \approx C_{\mathrm{app}}^{G}\left(t_{0}, t, \bar{T} ; K\right) \equiv \rho C^{G}\left(t_{0}, t, t_{0}+\delta^{G}\left(t_{0}\right) ; \frac{K}{\rho}\right)
$$

where $\delta^{G}\left(t_{0}\right)$ is the stochastic duration at time $t_{0}$ of the flow forward and the factor $\rho$ is given by

$$
\rho=\frac{G\left(t_{0}, \bar{T}\right)}{G\left(t_{0}, t_{0}+\delta^{G}\left(t_{0}\right)\right)}
$$

and $\bar{T} \geq t_{0}+\delta^{G}\left(t_{0}\right) \geq \min \left\{T_{i}\right\}_{i=1, \ldots, n}$, cf. section 3.3.3. The approximation for the price of a similar put option is given by

$$
P^{G}\left(t_{0}, t, \bar{T} ; K\right) \approx P_{\mathrm{app}}^{G}\left(t_{0}, t, \bar{T} ; K\right) \equiv \rho P^{G}\left(t_{0}, t, t_{0}+\delta^{G}\left(t_{0}\right) ; \frac{K}{\rho}\right)
$$




\subsubsection{A note on portfolios of flow forwards}

A portfolio of flow forwards does not principally differ from one single flow forward in the sense that both simply can be regarded as a sum (or indivisible portfolio) of single-delivery forwards. Thus, the stochastic duration for a portfolio of flow forwards is defined in exactly the same way as for one flow forward. Similarly, the pricing formula for options written on a portfolio of flow forwards is identical to the pricing formula for a single flow forward.

\section{Application to crude oil and electricity markets}

We consider two different markets. The crude oil market and the electricity market. In the crude oil market oil is delivered in the normal way for commodities, i.e. as discrete separated bulks. This is opposed to the electricity market where the commodity is delivered as a continuous flow. So, the electricity market is exactly an example where the flow feature of the forward contracts becomes relevant. The natural gas market has the same flow feature as the electricity market, and the demand pattern for the two commodities exhibit a similar degree of seasonal variation, so one could suspect that a model suited for the electricity market would be suited for the natural gas market as well. But we only mention this idea of similarity and do not investigate it further.

\subsection{The crude oil market}

The model is inspired by a three-factor model used in Schwartz (1997) and re-used in Miltersen and Schwartz (1998) in a different setting. Our model has three factors as well, but the difference from the original model is that we model a stochastic exchange rate instead of stochastic interest rates. Moreover, in the formulation of the diffusion term for the convenience yield we have added a constant $\eta \geq 0$ to an exponential function, which ensures that the convenience yield volatility will converge towards $\eta$ and not necessarily zero for the maturity date converging towards infinity, cf. the specification of $\sigma_{\epsilon}$ below. Specifically, we assume the following diffusion terms in our three-factor Gaussian model.

$$
\sigma_{S}(t)=\sigma_{S}\left(\begin{array}{c}
1 \\
0 \\
0
\end{array}\right), \quad \sigma_{x}(t)=\sigma_{x}\left(\begin{array}{c}
\rho_{S x} \\
\sqrt{1-\rho_{S x}^{2}} \\
0
\end{array}\right)
$$

and

$$
\sigma_{\epsilon}(t, s)=\sigma_{\epsilon}\left(e^{-\kappa_{\epsilon}(s-t)}+\eta\right)\left(\begin{array}{c}
\rho_{S \epsilon} \\
\frac{\rho_{x \epsilon}-\rho_{S x} \rho_{S \epsilon}}{\sqrt{1-\rho_{S x}^{2}}} \\
\sqrt{1-\rho_{S \epsilon}^{2}-\frac{\left(\rho_{x \epsilon}-\rho_{S x} \rho_{S \epsilon}\right)^{2}}{1-\rho_{S x}^{2}}}
\end{array}\right)
$$


Written as quadratic variation and mixed variation terms this means that the diffusion terms are given by

$$
\begin{aligned}
d\langle S\rangle_{t} & =\sigma_{S}^{2} S_{t}^{2} d t \\
d\langle x\rangle_{t} & =\sigma_{x}^{2} x_{t}^{2} d t \\
d\langle\epsilon(\cdot, s)\rangle_{t} & =\sigma_{\epsilon}^{2}\left(e^{-\kappa_{\epsilon}(s-t)}+\eta\right)^{2} d t \\
d\langle S, x\rangle_{t} & =\rho_{S x} \sigma_{S} \sigma_{x} S_{t} x_{t} d t \\
d\langle S, \epsilon(\cdot, s)\rangle_{t} & =\rho_{S \epsilon} \sigma_{S} \sigma_{\epsilon} S_{t}\left(e^{-\kappa_{\epsilon}(s-t)}+\eta\right) d t \\
d\langle x, \epsilon(\cdot, s)\rangle_{t} & =\rho_{x \epsilon} \sigma_{x} \sigma_{\epsilon} x_{t}\left(e^{-\kappa_{\epsilon}(s-t)}+\eta\right) d t
\end{aligned}
$$

Thus, using equation (3.19) one gets that

$$
\begin{gathered}
s_{F}(u, T)=\sigma_{S}\left(\begin{array}{l}
1 \\
0 \\
0
\end{array}\right)+\sigma_{x}\left(\begin{array}{c}
\rho_{S x} \\
\sqrt{1-\rho_{S x}^{2}} \\
0
\end{array}\right)+ \\
\sigma_{\epsilon}\left(\frac{1}{\kappa_{\epsilon}}\left(e^{-\kappa_{\epsilon}(T-u)}-1\right)-\eta(T-u)\right)\left(\begin{array}{c}
\rho_{S \epsilon} \\
\frac{\rho_{x \epsilon}-\rho_{S x} \rho_{S \epsilon}}{\sqrt{1-\rho_{S x}^{2}}} \\
\sqrt{1-\rho_{S \epsilon}^{2}-\frac{\left(\rho_{x \epsilon}-\rho_{S x} \rho_{S \epsilon}\right)^{2}}{1-\rho_{S x}^{2}}}
\end{array}\right)
\end{gathered}
$$

and

$$
\begin{aligned}
\left\|s_{F}(u, T)\right\|^{2} & =\left\|\sigma_{S}(u)+\sigma_{x}(u)-\int_{u}^{T} \sigma_{\epsilon}(u, s) d s\right\|^{2} \\
& =\left\|-\int_{u}^{T} \sigma_{\epsilon}(u, s) d s+\sigma_{S}(u)+\sigma_{x}(u)\right\|^{2} \\
& =\sigma_{\epsilon}^{2}\left(\frac{1}{\kappa_{\epsilon}^{2}}\left(1+e^{-2 \kappa_{\epsilon}(T-u)}-2 e^{-\kappa_{\epsilon}(T-u)}\right)+\eta^{2}(T-u)^{2}+\frac{2 \eta}{\kappa_{\epsilon}}\left(1-e^{-\kappa_{\epsilon}(T-u)}\right)(T-u)\right) \\
& -2\left(\rho_{S \epsilon} \sigma_{S} \sigma_{\epsilon}+\rho_{x \epsilon} \sigma_{x} \sigma_{\epsilon}\right)\left(\frac{1}{\kappa_{\epsilon}}\left(1-e^{-\kappa_{\epsilon}(T-u)}\right)+\eta(T-u)\right)+\sigma_{S}^{2}+\sigma_{x}^{2}+2 \rho_{S x} \sigma_{S} \sigma_{x}
\end{aligned}
$$

implying that

$$
\begin{aligned}
\Sigma_{F}^{2}=\int_{t_{0}}^{t}\left\|s_{F}(u, T)\right\|^{2} d u \\
=\sigma_{\epsilon}^{2}\left\{\frac{1}{\kappa_{\epsilon}^{2}}\left(\left(t-t_{0}\right)+H_{2 \kappa_{\epsilon}}(t)-H_{2 \kappa_{\epsilon}}\left(t_{0}\right)-2\left(H_{\kappa_{\epsilon}}(t)-H_{\kappa_{\epsilon}}\left(t_{0}\right)\right)\right)\right. \\
\left.\quad-\frac{1}{3} \eta^{2}\left((T-t)^{3}-\left(T-t_{0}\right)^{3}\right)+\frac{2 \eta}{\kappa_{\epsilon}}\left(\frac{1}{2}\left(T-t_{0}\right)^{2}-\frac{1}{2}(T-t)^{2}+J_{\kappa_{\epsilon}}\left(t_{0}\right)-J_{\kappa_{\epsilon}}(t)\right)\right\} \\
-2\left(\rho_{S \epsilon} \sigma_{S} \sigma_{\epsilon}+\rho_{x \epsilon} \sigma_{x} \sigma_{\epsilon}\right)\left\{\frac{1}{\kappa_{\epsilon}}\left(\left(t-t_{0}\right)+H_{\kappa_{\epsilon}}\left(t_{0}\right)-H_{\kappa_{\epsilon}}(t)\right)-\frac{\eta}{2}\left((T-t)^{2}-\left(T-t_{0}\right)^{2}\right)\right\} \\
+\left(\sigma_{S}^{2}+\sigma_{x}^{2}+2 \rho_{S x} \sigma_{S} \sigma_{x}\right)\left(t-t_{0}\right)
\end{aligned}
$$


where $H_{a}$ and $J_{a}$ (for a general constant $a$ ) for notational convenience are defined by

$$
\begin{aligned}
& H_{a}(u)=\frac{1}{a} e^{-a(T-u)} \Rightarrow \frac{\partial H^{*}}{\partial u}(u)=e^{-a(T-u)} \\
& J_{a}(u)=\frac{1}{a^{2}}\left(e^{-a(T-u)}+a(T-u) e^{-a(T-u)}\right) \Rightarrow \frac{\partial J^{*}}{\partial u}(u)=(T-u) e^{-a(T-u)}
\end{aligned}
$$

Given the eight parameters of the model, listed in Table 1, it is now possible to price singledelivery futures (or forward) European options by equations (3.18) \& (3.20) and European options on a futures portfolio by equation (3.25) \& (3.27). Or stated in an other way: given observed market prices on options on single-delivery futures it is possible to find prices on futures portfolios via equations (3.25) and (3.27).

\section{[INSERT Table 1]}

\subsection{The electricity market}

This model is an extended version of a model introduced by Bjerksund, Rasmussen, and Stensland (2000). Their model is used as a description of the (risk neutral) dynamics for futures and forward contracts on the Norwegian electricity market. The model has been implemented in Elviz, a risk management software marketed by the Norwegian company Viz Risk Management Services AS. To replicate their model in our setting we describe it as a two-factor model with the two factors equalling the spot prise and the forward convenience yield, but with perfect positive correlation between the two factors. A one-dimensional Wiener process under $\mathbf{Q}$ is the driving process. Using the notation from the original paper we can formulate the model in terms of the diffusion terms as

$$
\sigma_{S}(t)=\left(c+\frac{a}{b}\right)(1) \text { and } \sigma_{\epsilon}(t, s)=a(s-t+b)^{-2}(1)
$$

This is actually not the way Bjerksund, Rasmussen and Stensland formulate the model. They start by explicitly stating the volatility $s_{F}(t, T)$ of the prise process for the futures with maturity $T$. But the volatility can be calculated easily from the diffusion terms above as

$$
s_{F}(t, T)=\sigma_{S}(t)-\int_{t}^{T} \sigma_{\epsilon}(t, s) d s=c+\frac{a}{b}-a \int_{t}^{T}(s-t+b)^{-2} d s=c+a\left(\frac{1}{T-t+b}\right)
$$

For $T=t$ one gets that the volatility for $\sigma_{F}(t, t)$, i.e. the spot price process, is $c+\frac{a}{b}$, which indeed is how $\sigma_{S}(t)$ is specified above. For a general $T \geq t$ the $\operatorname{SDE}$ governing $(F(t, T))$ under $\mathbf{Q}$ is given by

$$
d F(t, T)=s_{F}(t, T) d W_{t}^{\mathbf{Q}}=\left(c+\frac{a}{T-t+b}\right) d W_{t}^{\mathbf{Q}}, \quad t \leq T
$$


Before extending the model we state it in terms of our own notation with $\sigma_{S} \equiv c+\frac{a}{b}, \sigma_{\epsilon} \equiv a$ and $b \equiv \frac{\sigma_{\epsilon}}{\sigma_{\epsilon}-c}$ as

$$
\sigma_{S}(t)=\sigma_{S}(1) \quad \text { and } \quad \sigma_{\epsilon}(t, s)=\sigma_{\epsilon}\left(s-t+\frac{\sigma_{\epsilon}}{\sigma_{\epsilon}-c}\right)^{-2}(1)=\sigma_{\epsilon}(s-t+b)^{-2}(1)
$$

The model is now extended by introducing exchange rate risk and the possibility of an arbitrary correlation between the spot price and the futures convenience yield along the lines of the Miltersen and Schwartz model. The driving process is thus a three-dimensional Q-Wiener process and we again allow for a possibly non-zero constant $\eta \geq 0$ in the formulation of $\sigma_{\epsilon}$. Specifically we assume the following diffusion terms

$$
\sigma_{S}(t)=\sigma_{S}\left(\begin{array}{c}
1 \\
0 \\
0
\end{array}\right), \quad \sigma_{x}(t)=\sigma_{x}\left(\begin{array}{c}
\rho_{S x} \\
\sqrt{1-\rho_{S x}^{2}} \\
0
\end{array}\right)
$$

and

$$
\sigma_{\epsilon}(t, s)=\sigma_{\epsilon}\left((s-t+b)^{-2}+\eta\right)\left(\begin{array}{c}
\rho_{s \epsilon} \\
\frac{\rho_{x \epsilon}-\rho_{S x} \rho_{S \epsilon}}{\sqrt{1-\rho_{S x}^{2}}} \\
\sqrt{1-\rho_{S \epsilon}^{2}-\frac{\left(\rho_{x \epsilon}-\rho_{S x} \rho_{S \epsilon}\right)^{2}}{1-\rho_{S x}^{2}}}
\end{array}\right)
$$

Written as quadratic variation and mixed variation terms this means that the diffusion terms are given by

$$
\begin{aligned}
d\langle S\rangle_{t} & =\sigma_{S}^{2} S_{t}^{2} d t \\
d\langle x\rangle_{t} & =\sigma_{x}^{2} x_{t}^{2} d t \\
d\langle\epsilon(\cdot, s)\rangle_{t} & =\sigma_{\epsilon}^{2}\left((s-t+b)^{-2}+\eta\right)^{2} d t \\
d\langle S, x\rangle_{t} & =\rho_{S x} \sigma_{S} \sigma_{x} S_{t} x_{t} d t \\
d\langle S, \epsilon(\cdot, s)\rangle_{t} & =\rho_{S \epsilon} \sigma_{S} \sigma_{\epsilon} S_{t}\left((s-t+b)^{-2}+\eta\right) d t \\
d\langle x, \epsilon(\cdot, s)\rangle_{t} & =\rho_{x \epsilon} \sigma_{x} \sigma_{\epsilon} x_{t}\left((s-t+b)^{-2}+\eta\right) d t
\end{aligned}
$$

Thus, by using equation (3.19), one gets that

$$
\begin{aligned}
\left\|s_{F}(u, T)\right\|^{2}= & \left\|\sigma_{S}(u)+\sigma_{x}(u)-\int_{u}^{T} \sigma_{\epsilon}(u, s) d s\right\|^{2} \\
= & \sigma_{S}^{2}+\sigma_{x}^{2}+2 \rho_{S x} \sigma_{S} \sigma_{x}+\sigma_{\epsilon}^{2}\left(\left[(s-u+b)^{-1}\right]_{u}^{T}-\eta(T-u)\right)^{2} \\
& +2\left(\left[(s-u+b)^{-1}\right]_{u}^{T}-\eta(T-u)\right)\left(\rho_{S \epsilon} \sigma_{S} \sigma_{\epsilon}+\rho_{x \epsilon} \sigma_{x} \sigma_{\epsilon}\right) \\
= & \sigma_{S}^{2}+\sigma_{x}^{2}+2 \rho_{S x} \sigma_{S} \sigma_{x}+\sigma_{\epsilon}^{2}\left((T-u+b)^{-2}+b^{-2}-2(b(T-u+b))^{-1}\right) \\
& +\sigma_{\epsilon}^{2}\left(\eta^{2}(T-u)^{2}-2 \eta(T-u)\left((T-u+b)^{-1}-b^{-1}\right)\right) \\
& +2\left((T-u+b)^{-1}-b^{-1}-\eta(T-u)\right)\left(\rho_{S \epsilon} \sigma_{S} \sigma_{\epsilon}+\rho_{x \epsilon} \sigma_{x} \sigma_{\epsilon}\right)
\end{aligned}
$$


implying that

$$
\begin{aligned}
\Sigma_{F}^{2}= & \int_{t_{0}}^{t}\left\|s_{F}(u, T)\right\|^{2} d u \\
= & \left(\sigma_{S}^{2}+\sigma_{x}^{2}+2 \rho_{S x} \sigma_{S} \sigma_{x}\right)\left(t-t_{0}\right)+\sigma_{\epsilon}^{2}\left(\left[(T-u+b)^{-1}\right]_{t_{0}}^{t}+b^{-2}\left(t-t_{0}\right)+\frac{2}{b}[\log (T-u+b)]_{t_{0}}^{t}\right) \\
& -\sigma_{\epsilon}^{2}\left(\frac{\eta^{2}}{3}\left((T-t)^{3}-\left(T-t_{0}\right)^{3}\right)+2 \eta[-(T-u)+b \log (T-u+b)]_{t_{0}}^{t}+\frac{\eta}{b}\left((T-t)^{2}-\left(T-t_{0}\right)^{2}\right)\right) \\
& \left.-2\left(\rho_{S \epsilon} \sigma_{S} \sigma_{\epsilon}+\rho_{x \epsilon} \sigma_{x} \sigma_{\epsilon}\right)\left(\frac{1}{b}\left(t-t_{0}\right)+[\log (T-u+b)]\right)_{t_{0}}^{t}-\frac{\eta}{2}\left((T-t)^{2}-\left(T-t_{0}\right)^{2}\right)\right)
\end{aligned}
$$

Given the eight parameters of the model, listed in Table 2 below, it is now possible to price singledelivery forwards (or futures) European options by equations (3.18) and (3.20) and European options on flow forwards by equations (3.41) and (3.43). Assume that a single-delivery forward is defined as a forward for delivery on one single future day. This implies that all forward contracts with a delivery period extending one day is defined as a flow forward. As most electricity forwards have delivery periods equalling week(s), month(s) or quarter(s) of a year it is obvious that most forwards are, by this assumption, flow forwards. This naturally implies that most exchange traded electricity options are options with a flow forward as underlying contract. Thus, in the electricity market one would use equations (3.41) and (3.43) the opposite way compared to the oil market: In the oil market one would price options on futures portfolios based on the prices of single-delivery futures, while in the electricity market one would have market prices on flow forward options as the basis. And from this basis it is possible to price OTC single-delivery forwards and thus also OTC flow forward options.

\section{[INSERT Table 2 ]}

\section{Monte Carlo simulation}

\subsection{Monte Carlo simulation and price comparison}

In order to investigate the precision of the approximation approach for valuing options on futures portfolios we have performed Monte Carlo simulation ${ }^{5}$ to find the prices of 11 call and 11 put options with the same underlying portfolio as in section 4.1, i.e. the three factor model with a futures portfolio consisting of 6 Brent crude futures with monthly delivery through the period October 2003-March 2004. The prices are calculated as of 30th May, 2003 $\left(t_{0}\right)$, with the options expiring at 10th September, $2003(t)$. The options only differ by the strike level which, as a percentage of the ATM strike level (157.46 DKK), belongs to the set $\{70 \%, 80 \%, 85 \%, 90 \%, 95 \%, 100 \%, 105 \%, 110 \%, 115 \%, 120 \%, 130 \%\}$.

\footnotetext{
${ }^{5} 50,000$ pairs of antithetic sample paths have been simulated by an Euler approximation of the underlying futures' SDEs to price each of the options. The length of the time step was one calendar day. The calculations are performed in MAPLE.
} 
We have considered approximate option prices with three different durations for the representative single-delivery futures, namely $\delta^{F}, \delta^{F_{A}}$ and the simple average of the two $\frac{\delta^{F}+\delta^{F_{A}}}{2}$. These prices are denoted by $C\left[\delta^{F}\right], C\left[\delta^{F_{A}}\right]$ and $C\left[\frac{\delta^{F}+\delta^{F_{A}}}{2}\right]$, respectively, in the call case and analogously by $P\left[\delta^{F}\right], P\left[\delta^{F_{A}}\right]$ and $P\left[\frac{\delta^{F}+\delta^{F} A}{2}\right]$ in the put case. Moreover, we have considered the arithmetic average between the prices obtained by $\delta^{F}$ and $\delta^{F_{A}}$. This price average exploits the observed fact that the $\delta^{F}$-method has a negative price bias whereas the $\delta^{F_{A}}$-method has a positive price bias.

At last, after having simulated and calculated all prices, we ran a simple OLS regression by regressing the whole sample of $22 \mathrm{MC}$ prices on the corresponding prices $C\left[\delta^{F}\right]$ and $C\left[\delta^{F_{A}}\right]$ for the call prices and $P\left[\delta^{F}\right]$ and $P\left[\delta^{F_{A}}\right]$ for the put prices. Denoting the OLS parameter belonging to the $\left[\delta^{F}\right]$-variable $\left(\left[\delta^{F_{A}}\right]\right.$-variable) by $v_{1}\left(v_{2}\right)$ we found the OLS estimates to be $\hat{v}_{1}=0.436$ and $\hat{v}_{2}=0.573$. Thus, more weight is attached to the $\left[\delta^{F_{A}}\right]$-variable. However, the hypothesis $H_{0}: v_{1}=v_{2}=0.5$ of equal weights could not be rejected. It was accepted with a test probability of $1-F_{F(2,20)}\left(\frac{(0.1110-0.1045) / 2}{0.1045 / 20}\right)=0.55$. In practice the interest is mainly in options that are close to being at-the-money. All methods, except the $\delta^{F}$-method, appear to perform with a desirable accuracy in this region.

It is obvious that the prices given by our approximate option pricing formula is a non-linear function of the portfolio's stochastic duration $\delta^{F}$ or $\delta^{F_{A}}$. Hence, one could also suspect that the linear relationship among the variables in the above OLS regression is not valid. However, we found neither signs of misspecification (applying Ramsey's RESET test), residual autocorrelation (applying Harvey's F-test for first-order autocorrelation) nor residual conditional heteroscedasticity (applying Engel's F-test for first-order ARCH). Consequently, the linear relationship seems applicable for practical purposes. Taking the call case as an example, we conclude that it appears reasonable to maximize the precision of the approximate option pricing formula by a direct convex combination of $C\left[\delta^{F}\right]$ and $C\left[\delta^{F_{A}}\right]$ instead of searching for an optimal convex combination of $\delta^{F}$ and $\delta^{F_{A}}$ that could be used in the $C[\cdot]$ function as the "optimal" approximate option price. According to our results, cf. Tables 3 and 4 and the test of $H_{0}$, choosing the convex combination $v_{1}=v_{2}=0.5$ as default is not a bad choice.

[INSERT Table 3]

[INSERT Table 4 ]

Additionally, it is a useful guide that the $\delta^{F}$-method seems to produce prices that are too low while the $\delta^{F_{A}}$-method seems to produce prices that are too high. 


\subsection{Details about the example}

The assumed portfolio consists of the 6 futures contracts for delivery of $\frac{1}{6}$ barrel in either of the months October, November, December 2003 and January, February and March 2004. Thus, a total of 1 barrel is delivered during the period October 2003-March 2004. The exercise price, expressed in DKK, is set equal to the futures price of the contract with time to maturity equal to the stochastic duration of the portfolio. By doing so the option is by construction at the money when the investor initially enters into it. The basic IPE data for the example are presented in Table 5 . The contracts numbered $4,5, \ldots, 9$ constitute the portfolio.

Additional information needed is taken from the Danish Central Bank (Nationalbanken) and the US Central Bank (Federal Reserve) according to whom the official exchange rate as of 30th May 2003 was 628.02 DKK/100 USD, the 6-month CIBOR interest rate was $2.30 \%$ p.a. and the 6 -month Eurodollar interbank interest rate was $1.15 \%$ p.a. These 6 -months rates have been used as flat rates throughout the whole period of interest, thus assuming constant interest rates in this period.

The parameters $\sigma_{S}, \sigma_{\epsilon}, \rho_{S \epsilon}, \kappa_{\epsilon}$ and $\eta$ have been estimated implicitly by finding the combination of parameter values that minimizes the sum of squared deviations between squared annual model volatility (i.e. $\frac{\Sigma_{F_{i}}^{2}}{t_{i}-t_{0}}$ for $i=1,2, \ldots, 11$ ) and squared observed implied annual option volatility for the 11 observed implied option volatilities reported in Table 5. The resulting parameter estimates are given in Table 6.

\section{[INSERT Table 5}

\section{[INSERT Table 6]}

\section{Conclusion}

In this paper we have shown how to find the stochastic duration of energy futures portfolios and flow forwards and how to approximately price European options with them as underlying instruments, also when the options are denominated in another currency than the trading currency for the underlying instrument. This has been done in a HJM framework which is well suited for modelling the term structure in energy futures markets. Making assumptions about log-Gaussian spot prices and exchange rates and Gaussian convenience yields, we found explicit pricing formulas for the futures portfolio and flow forward options. Proposals for suitable models for the crude oil and electricity markets have been provided.

The framework is quite general and still analytically tractable. The generality is underpinned by the fact that prices on forwards and futures do not have to follow a log-Gaussian process, as 
they do in our examples. As long as they follow a process where it is possible to price European options on single-delivery forwards or futures analytically, it allows application of our option pricing approximation to options on a (flow) forward or a futures portfolio. Thus, prices can be allowed to follow e.g. a CIR-like process, giving rise to non-central $\chi^{2}$ distributed prices, or exponential affine term structure models that are well-known from the fixed income literature.

Thus, it is possible to extend the framework to a multi-commodity situation with several energy commodities. In this situation it is of course still essential to be able to calculate the duration of any (multi-commodity) portfolio as a combined risk measure for the portfolio. It could be calculated in an extended model compared to our model in this paper, but still along exactly the same lines outlined here. Option sensitivity parameters, which are highly relevant for practical hedging purposes, could still be easily calculated due to the analytical tractability of the model. Moreover, it would be possible to value single-commodity and cross-commodity energy options in the same model, which is an attractive and consistency-procuring feature.

\section{References}

Andreasen, J. (1995): "Pricing by arbitrage in an international economy," in Research in International Business and Finance, pages 93-116. JAI Press.

Buerksund, P., H. Rasmussen, and G. Stensland (2000): "Valuation and Risk Management in the Norwegian Electricity Market," Working Paper, Norwegian School of Economics and Business Administration, Bergen, Norway.

BJöRK, T. (1998): Arbitrage theory in continuous time, Oxford University Press, Oxford, Great Britain.

Brennan, M. J. (1991): "The price of convenience and the valuation of commodity contingent claims," in Lund, D. and B. Øksendal, editors, Stochastic Models and Option Values, pages 33-72. Elsevier Science Publishers.

Carverhill, A. (1994): "When is the short rate Markovian?," Mathematical Finance, $4(4): 305-312$.

Heath, D., R. Jarrow, And A. J. Morton (1992): "Bond pricing and the term structure of interest rates: A new methodology for contingent claims valuation," Econometrica, 60(1):77-106.

Jamshidian, F. (1989): "An Exact Bond Option Formula," The Journal of Finance, 44(1):205209. 
Longstaff, F. A. (1993): "The valuation of options on coupon bonds," Journal of Banking and Finance, 17:27-42.

Longstaff, F. A. And E. S. Schwartz (1992): "Interest rate volatility and the term structure: A two-factor general equilibrium model," The Journal of Finance, 47(4):1259-1282.

Miltersen, K. R. And E. S. Schwartz (1998): "Pricing of Options on Commodity Futures with Stochastic Term Structures of Convenience Yields and Interest Rates," Journal of Financial and Quantitative Analysis, 33(1):33-59.

Munk, C. (1999): "Stochastic Duration and Fast Coupon Bond Option Pricing in Multi-Factor Models," Review of Derivatives Research, 3(2):157-182.

Schwartz, E. S. (1997): "The stochastic behavior of commodity prices: Implications for valuations and hedging," The Journal of Finance, 52(3):923-973. Elsevier North-Holland.

Singleton, K. And L. Umantsev (2002): "Pricing Coupon-Bond Options and Swaptions in Affine Term Structure Models," Mathematical Finance, 12:427-446. 
Table 1: The eight parameters for the oil market model classified after if they can be estimated by inference based on observed variables. In this case the parameter is marked by a $\dagger$ as Observable. Otherwise it is marked as Non-observable.

\begin{tabular}{ccc}
\hline Parameter & Observable & Non-observable \\
\hline$\sigma_{S}$ & $\dagger$ & \\
$\sigma_{x}$ & $\dagger$ & \\
$\rho_{S x}$ & $\dagger$ & $\dagger$ \\
$\sigma_{\epsilon}$ & & $\dagger$ \\
$\kappa_{\epsilon}$ & $\dagger$ \\
$\rho_{S \epsilon}$ & & $\dagger$ \\
$\rho_{x \epsilon}$ & & $\dagger$ \\
$\eta$ & &
\end{tabular}

Table 2: The eight parameters for the electricity market model classified after if they can be estimated by inference based on observed variables. In this case the parameter is marked by a $\diamond$ as Observable. Otherwise it is marked as Non-observable.

\begin{tabular}{ccc}
\hline Parameter & Observable & Non-observable \\
\hline$\sigma_{S}$ & $\diamond$ & \\
$\sigma_{x}$ & $\diamond$ & \\
$\rho_{S x}$ & $\diamond$ & $\diamond$ \\
$\sigma_{\epsilon}$ & & $\diamond$ \\
$b$ & & $\diamond$ \\
$\rho_{S \epsilon}$ & & $\diamond$ \\
$\rho_{x \epsilon}$ & & $\diamond$ \\
$\eta$ & & \\
\hline
\end{tabular}


Table 3: Results of MC simulating the values of call options on the futures portfolio, consisting of six Brent oil futures of different maturities, from section 2.5. 11 Different strike prices have been used, ranging from $70 \%$ to $130 \%$ of the ATM strike level $\left(15 \% .46\right.$ DKK). $\hat{v}_{1}=0.426$ and $\hat{v}_{2}=0.573$.

\begin{tabular}{c|c|ccccc}
\hline Strike & Call price & \multicolumn{5}{|c}{ Price deviation } \\
\hline & $\mathrm{MC}$ & $C\left[\delta^{F}\right]$ & $C\left[\delta^{F_{A}}\right]$ & $C\left[\frac{\delta^{F}+\delta^{F}}{2}\right]$ & $\left.\frac{C\left[\delta^{F}\right]+C\left[\delta^{F}\right]}{2}\right]$ & $\hat{v}_{1} C\left[\delta^{F}\right]+\hat{v}_{2} C\left[\delta^{F_{A}}\right]$ \\
\hline $70 \%$ & 46.66 & 0.14 & 0.03 & 0.08 & 0.09 & 0.03 \\
$80 \%$ & 31.63 & 0.02 & -0.01 & 0.00 & 0.02 & -0.02 \\
$85 \%$ & 24.74 & -0.07 & -0.03 & -0.06 & -0.05 & -0.06 \\
$90 \%$ & 18.50 & -0.08 & 0.05 & -0.03 & -0.02 & -0.02 \\
$95 \%$ & 13.32 & -0.19 & 0.01 & -0.11 & -0.09 & -0.09 \\
$100 \%$ & 9.12 & -0.20 & 0.04 & -0.10 & -0.08 & -0.07 \\
$105 \%$ & 5.84 & -0.06 & 0.18 & 0.04 & 0.07 & 0.08 \\
$110 \%$ & 3.72 & -0.15 & 0.08 & -0.06 & -0.04 & -0.02 \\
$115 \%$ & 2.06 & 0.05 & 0.23 & 0.13 & 0.15 & 0.16 \\
$120 \%$ & 1.11 & 0.09 & 0.23 & 0.14 & 0.16 & 0.17 \\
$130 \%$ & 0.35 & 0.00 & 0.06 & 0.03 & 0.03 & 0.03 \\
\hline SSD & & 0.146 & 0.154 & 0.077 & 0.077 & 0.080 \\
\hline
\end{tabular}


Table 4: Results of MC simulating the values of put options on the futures portfolio, consisting of six Brent oil futures of different maturities, from section 2.5. 11 Different strike prices have been used, ranging from $70 \%$ to $130 \%$ of the ATM strike level $\left(15 \% .46\right.$ DKK). $\hat{v}_{1}=0.426$ and $\hat{v}_{2}=0.573$.

\begin{tabular}{c|c|ccccc}
\hline Strike & Put price & \multicolumn{5}{|c}{ Price deviation } \\
\hline & MC & $P\left[\delta^{F}\right]$ & $P\left[\delta^{F_{A}}\right]$ & $P\left[\frac{\delta^{F}+\delta^{F}}{2}\right]$ & $\left.\frac{P\left[\delta^{F}\right]+P\left[\delta^{F_{A}}\right]}{2}\right]$ & $\hat{v}_{1} P\left[\delta^{F}\right]+\hat{v}_{2} P\left[\delta^{F_{A}}\right]$ \\
\hline $70 \%$ & 0.04 & 0.01 & 0.02 & 0.01 & 0.01 & 0.01 \\
$80 \%$ & 0.53 & 0.02 & 0.11 & 0.06 & 0.06 & 0.07 \\
$85 \%$ & 1.49 & -0.10 & 0.07 & -0.03 & -0.03 & -0.01 \\
$90 \%$ & 3.11 & -0.16 & 0.09 & -0.05 & -0.04 & -0.02 \\
$95 \%$ & 5.73 & -0.25 & 0.07 & -0.11 & -0.09 & -0.07 \\
$100 \%$ & 9.35 & -0.25 & 0.11 & -0.09 & -0.07 & -0.05 \\
$105 \%$ & 14.05 & -0.27 & 0.10 & -0.11 & -0.09 & -0.07 \\
$110 \%$ & 19.52 & -0.13 & 0.22 & 0.03 & 0.05 & 0.05 \\
$115 \%$ & 25.90 & -0.14 & 0.16 & -0.01 & 0.01 & 0.01 \\
$120 \%$ & 32.72 & -0.05 & 0.21 & 0.06 & 0.08 & 0.07 \\
$130 \%$ & 47.53 & -0.07 & 0.12 & 0.02 & 0.02 & -0.01 \\
\hline SSD & & 0.280 & 0.185 & 0.045 & 0.034 & 0.025 \\
\hline
\end{tabular}

Table 5: Futures and option data from 30th May 2003 from IPE used for calculating the price of European options on a futures portfolio consisting of contracts No. 4,5, ., 9. Prices are in

\begin{tabular}{|c|c|c|c|c|c|c|c|c|}
\hline$i$ & Contract & Price & Strike & Call price & Put price & Imp. vol., \% p.a. & Option expiry $t_{i}$ & Futures expiry $T_{i}$ \\
\hline 1 & Jul 2003 & 26.32 & 26.50 & 0.69 & 0.87 & 40.66 & 10/06 2003 & 13/06 2003 \\
\hline 2 & Aug 2003 & 26.00 & 26.00 & 1.23 & 1.23 & 34.56 & 11/07 2003 & 16/07 2003 \\
\hline 3 & Sep 2003 & 25.74 & 25.50 & 1.61 & 1.37 & 32.33 & 11/08 2003 & $14 / 082003$ \\
\hline 4 & Oct 2003 & 25.51 & 25.50 & 1.66 & 1.65 & 30.50 & 10/09 2003 & 15/09 2003 \\
\hline 5 & Nov 2003 & 25.28 & 25.50 & 1.72 & 1.94 & 29.49 & $13 / 102003$ & $16 / 102003$ \\
\hline 6 & Dec 2003 & 25.04 & 25.00 & 1.99 & 1.95 & 29.40 & 10/11 2003 & $13 / 112003$ \\
\hline 7 & Jan 2004 & 24.77 & 25.00 & 1.97 & 2.20 & 28.68 & $11 / 122003$ & $16 / 122003$ \\
\hline 8 & Feb 2004 & 24.52 & 24.50 & 2.16 & 2.14 & 27.87 & $12 / 012004$ & 15/01 2004 \\
\hline 9 & Mar 2004 & 24.29 & 24.50 & 2.02 & 2.23 & 26.10 & 09/02 2004 & $12 / 022004$ \\
\hline 10 & Apr 2004 & 24.08 & 24.00 & 2.22 & 2.14 & 25.68 & 11/03 2004 & 16/03 2004 \\
\hline 11 & May 2004 & 23.88 & 24.00 & 2.18 & 2.30 & 25.29 & 08/04 2004 & $15 / 042004$ \\
\hline
\end{tabular}


Table 6: Estimates of the parameters of the oil market model $\sigma_{S}, \sigma_{\epsilon}, \rho_{S \epsilon}, \kappa_{\epsilon}, \eta, \sigma_{x}$ and $\rho_{S x} . \rho_{x \epsilon}$ has been set to zero. For comparison, estimated values for $\sigma_{S}, \sigma_{\epsilon}, \rho_{S \epsilon}, \kappa_{\epsilon}$ for $N Y M E X$ crude oil futures from Schwartz (1997) are reported too. Also the SSD between observed squared annual implied IPE option volatility and squared annual model volatility is reported (it relates to the first five parameters only).

\begin{tabular}{c|cc}
\hline Parameter estimate & Estimated value & Schwartz (1997) \\
\hline$\hat{\sigma}_{S}$ & 0.4409 & 0.344 \\
$\hat{\sigma}_{\epsilon}$ & 1.7923 & 0.372 \\
$\hat{\rho}_{S \epsilon}$ & 0.9850 & 0.915 \\
$\hat{\kappa}_{\epsilon}$ & 8.5172 & 1.045 \\
$\hat{\eta}$ & 0 & - \\
$\hat{\sigma}_{x}$ & 0.1104 & - \\
$\hat{\rho}_{S x}$ & -0.0015 & - \\
$\hat{\rho}_{x \epsilon}$ & 0 & - \\
$\mathrm{SSD}$ & $6.88 \cdot 10^{-5}$ & - \\
\hline
\end{tabular}


INSTITUT FOR FINANSIERINGs working papers siden 2000:

WP 2000-1 Bjarne Astrup Jensen and Carsten Sørensen: Paying for minimum interest rate guarantees: Who should compensate who?

WP 2000-2 Jan Jakobsen and Ole Sørensen: Decomposing and testing Long-run Returns with an application to initial public offerings in Denmark.

WP 2000-3 Jan Jakobsen and Torben Voetmann: Volatility-Adjusted Performance An Alternative Approach to Interpret Long-Run Returns.

WP 2000-4 Jan Jakobsen and Torben Voetmann: Post-Acquisition Performance in the Short and Long-Run Evidence from the Copenhagen Stock Exchange 1993-1997.

WP 2000-5 Ken L. Bechmann and Johannes Raaballe: A Regulation of Bids for Dual Class Shares. Implication: Two Shares - One Price.

WP 2000-6 Torben Voetmann: Changes in the Bid-Ask Componets Around Earnings Announcemtents: Evidence from the Copenhagen Stock Exchange.

WP 2000-7 Henrik Lando: The Optimal Standard of Proof in Criminal Law When Both Fairness and Deterrence Are Social Aims.

WP 2000-8 Jesper Rangvid and Carsten Sørensen: Convergence in the ERM and Declining Numbers of Common Stochastic Trends.

WP 2000-9 Claus Munk and Carsten Sørensen: Optimal Consumption and Investment Strategies with Stochastic Interest Rates.

WP 2000-10 Henrik Lando and Caspar Rose: On Specific Performance in Civil Law and Enforcement Costs.

WP 2000-11 Henrik Lando: Ny lov om jordforurening i økonomisk belysning.

WP 2001-1 Michael Møller, Claus Parum og Thomas Sørensen: Den ny pensionsafkastbeskatningslov.

WP 2001-2 Bjarne Astrup Jensen: Mean variance efficient portfolios by linear programming: A review of some portfolio selection criteria of Elton, Gruber and Padberg.

WP 2001-3 Caspar Rose: Impact of Investor Meetings/Presentations on Share 
Prices, Insider Trading and Securities Regulation.

WP 2001-4 Caspar Rose: Corporate Financial Performance and the Use of Takeover Defenses.

WP 2001-5 Shubhashis Gangopadhyay and Clas Wihlborg: The Impact of Bankruptcy Rules on Risky Project Choice and Skill Formation under Credit Rationing.

WP 2001-6 Claus Munk, Carsten Sørensen \& Tina Nygaard Vinther: Portfolio Choice under Inflation: Are Popular Recommendations Consistent with Rational Behaviour?

WP 2001-7 Ken L. Bechmann: Evidence on the Limits of Arbitrage: Short Sales, Price Pressure, and the Stock Price Response to Convertible Bond Calls.

WP 2001-8 Michael Møller \& Caspar Rose: Legal pre-emption rights as calloptions, redistribution and efficiency loss.

WP 2001-9 Peter Raahauge: Empirical Rationality in the Stock Market.

WP 2002-1 Bjarne Astrup Jensen: On valuation before and after tax in no arbitrage models: Tax neutrality in the discrete time model.

WP 2002-2 Ken L. Bechmann: Price and Volume Effects Associated with Changes in the Danish Blue-Chip Index - The KFX Index.

WP 2002-3 Steen Thomsen and Caspar Rose: Foundation ownership and financial performance. Do companies need owners?

WP 2002-4 Martin Richter and Carsten Sørensen: Stochastic Volatility and Seasonality in Commodity Futures and Options: The Case of Soybeans.

WP 2002-5 Caspar Rose: Aktiemarkedets reaktion på indførelsen af incitamentsprogrammer.

WP 2002-6 Caspar Rose: Impact of Takeover Defenses on Managerial Incentives.

WP 2002-7 ～Ken L. Bechmann og Peter Løchte Jørgensen: Optionsaflønning i danske børsnoterede selskaber.

WP 2002-8 Jesper Rangvid: Output and Expected Returns - a multicountry study.

WP 2002-9 Jonas Aziz Bhatti og Michael Møller: Pensionsafkastbeskatning og optimal porteføljesammensætning. 
WP 2003-1 Bjarne Florentsen, Michael Møller and Niels Chr. Nielsen: Reimbursement of VAT on written-off Receivables.

WP 2003-2: $\quad$ Ken L. Bechmann and Peter Løchte Jørgensen: The Value and Incentives of Option-based Compensation in Danish Listed Companies.

WP 2004-1 Ken L. Bechmann and Johannes Raaballe: The Difference Between Stock Splits and Stock Dividends - Evidence from Denmark.

WP 2004-2 Caspar Rose: Bestyrelsessammensætning og finansiel performance i danske børsnoterede virksomheder - Er Nørbyrapportens anbefalinger til gavn for aktionærerne?

WP 2004-3 Jens Lunde: Lack of balance in after-tax returns - lack of tenure neutrality. The Danish case.

WP 2004-4 Peter Raahauge: Upper Bounds on Numerical Approximation Errors.

WP 2004-5 Peter Raahauge: Higher-Order Finite Element Solutions of Option Prices.

WP 2004-6 Anders Holst \& Morten Nalholm: Modelling Callable Annuity Bonds with Interest-Only Optionality.

WP 2004-7 Bent Jesper Christensen \& Peter Raahauge: Latent Utility Shocks in a Structural Empirical Asset Pricing Model.

WP 2004-8 Carsten Sørensen and Anders Bjerre Trolle: Dynamic asset allocation and latent variables.

WP 2004-9 David Lando and Allan Mortensen: On the Pricing of Step-Up Bonds in the European Telecom Sector.

WP 2004-10 Thomas Lyse Hansen and Bjarne Astrup Jensen: Energy Options in an HJM Framework. 